\title{
Larger IOR effects following forget than following remember instructions depend on exogenous attentional withdrawal and target localization
}

\author{
Tracy L. Taylor • Jonathan M. Fawcett
}

Published online: 27 May 2011

(C) Psychonomic Society, Inc. 2011

\begin{abstract}
When words are onset in the visual periphery, inhibition of return (IOR) for a subsequent target is larger when those words receive an intervening forget instruction than when they receive a remember instruction Taylor (Quarterly Journal of Experimental Psychology, 58A, 613$629,2005)$. The present study manipulated the allocation of endogenous and exogenous attention to assess the source of the forget $>$ remember IOR difference. We determined that the forget $>$ remember IOR difference likely arises from the differential withdrawal of exogenous - rather than endogenous - attention. Furthermore, this forget $>$ remember IOR difference occurs only when a spatially compatible localization response is required; it does not occur when a simple detection response or a perceptual discrimination is required. This suggests that the forget $>$ remember difference in the magnitude of IOR is not due to differences in perceptual/ attentional processing. Instead, an instruction to remember or forget biases spatial responses in accordance with whether a location has previously contained relevant or irrelevant information. We suggest that directed forgetting in an itemmethod paradigm is not accomplished by changes in attention; rather, the changes in attention are coincident with changes in memory and may serve to bias later responses away from a source of unreliable information.
\end{abstract}

Keywords Attention and memory · Inhibition of return

T. L. Taylor $(\bowtie) \cdot$ J. M. Fawcett

Department of Psychology, Life Sciences Centre,

Dalhousie University,

1355 Oxford Street,

Halifax, Nova Scotia B3H 4R2, Canada

e-mail: ttaylor2@dal.ca

\section{Introduction}

Although we tend to think of forgetting as a failure of memory, it often operates in the service of memory (e.g., Bjork \& Bjork, 1996; Bjork, 1972). This is the case, for example, when information initially intended for retention becomes outdated or irrelevant. Intentional forgetting prevents this information from gaining access to limited cognitive resources. In this way, intentional forgetting minimizes interference from irrelevant information and encourages the retention of relevant information (Bjork, 1970, 1989).

Intentional forgetting in the laboratory is typically investigated using either the list method or the item method (Basden \& Basden, 1998; MacLeod, 1999); the present study is concerned exclusively with the item method. In an item-method task, participants are presented with a list of words, one at a time, each followed with equal probability by an instruction to remember or to forget that word. A directed forgetting effect is revealed as better memory for remember than for forget words (see MacLeod, 1998, for a review) and cannot be accounted for by demand characteristics (MacLeod, 1999).

Historically, item-method directed forgetting has been explained by selective rehearsal at encoding (e.g., Basden, Basden, \& Gargano, 1993; Bjork \& Woodward, 1973; Gottlob, Golding, \& Hauselt, 2006; MacLeod, 1999; Wetzel \& Hunt, 1977). The notion is that each word is held in working memory via maintenance rehearsal until the memory instruction is received (e.g., Woodward, Bjork, \& Jongeward, 1973). If the instruction is to remember the word, then elaborative rehearsal is engaged to commit that word to memory; if, instead, the instruction is to forget the word, then that word is eliminated from the rehearsal set. In this way, all words receive a minimal amount of perceptual 
processing and maintenance rehearsal, but only remember words receive additional semantic processing and conceptual elaboration. Selective rehearsal of remember items over forget items not only accounts for directed forgetting effects in both recall and recognition (Basden et al., 1993; MacLeod, 1989), but also for the failure to find remember-forget differences on data-driven implicit tests of memory (e.g., Basden et al., 1993; MacLeod, 1999) and for "know" responses within the remember-know paradigm (e.g., Gardiner, Gawlick, \& Richardson-Klavehn, 1994; Tekcan \& Aktürk, 2001).

Despite the explanatory power of this selective-rehearsal hypothesis, it does not postulate exactly how forget words are eliminated from the rehearsal set. One is led to believe that maintenance rehearsal simply ceases and no other cognitive operations are performed on these representations, such that they decay passively from memory. An alternative to this "rehearsal ceases" view, which conceptualizes forgetting as the result of a passive decay process, is the "attentional withdrawal" view, which conceptualizes forgetting as the result of an active cognitive-control process (e.g., Fawcett \& Taylor, 2008, 2010; Zacks, Radvansky, \& Hasher, 1996). According to the attentional withdrawal view, selective rehearsal of remember items can occur because active control mechanisms are engaged to prevent irrelevant forget information from having continued access to limited-capacity working memory resources. The notion is that upon receipt of a forget instruction, attention withdraws from the representation of the forget item in working memory to help expunge it from memory (e.g., Zacks et al., 1996). Far from an effortless cessation of rehearsal, this active withdrawal of attention forcibly removes processing resources from the forget item, thereby limiting its commitment to long-term memory and freeing limited-capacity resources for the rehearsal of remember items (e.g., Roediger \& Crowder, 1972).

To determine whether attention is differentially withdrawn from the spatial representation that forms part of the episodic memory trace for peripherally presented forget and remember items (Hourihan, Goldberg, \& Taylor, 2007), Taylor (2005, and see also the Erratum; Fawcett \& Taylor, 2010) used the phenomenon of inhibition of return (IOR; Posner \& Cohen, 1984). IOR refers to longer reaction times (RTs) that occur for onset targets that appear after a relatively long delay (>300 ms) in the same, rather than in a different, location relative to a preceding peripheral onset cue (Posner \& Cohen, 1984). Although the IOR effect can co-occur with endogenous attention (see Berlucchi, Chelazzi, \& Tassinari, 2000; Chica, 2008; Chica, Lupiáñez, \& Bartolomeo, 2006; Lupiáñez et al., 2004), it is typically measurable in RTs only after attention has been withdrawn (see, e.g., Danziger \& Kingstone, 1999).

Recognizing that IOR may sometimes be a kind of "footprint" left behind following attentional withdrawal, Taylor (2005, see also the Erratum; Fawcett \& Taylor, 2010) used IOR to explore the differential withdrawal of attention from peripherally presented forget and remember words. Taylor employed an item-method directed forgetting paradigm wherein words were presented one at a time to the left or right of central fixation, followed by a tone that instructed participants to remember or forget the preceding word. After a delay, a target requiring a speeded localization response was presented with equal probability to the left or right. RTs for target localization were measured as a function of whether the target occurred in the same location as the preceding peripheral word (cued) or in a different location (uncued). The results revealed an IOR effect of larger magnitude following forget instructions than following remember instructions. As compared to a no-memory control condition, the magnitude of the observed IOR effect was larger than when words were remember instructed and smaller than when words were forget instructed. This finding was interpreted as evidence that attention is removed more readily from the mental representation of peripherally presented forget words than from the mental representation of peripherally presented remember words (indeed, attention may, in fact, continue to dwell on the remember words).

The present study was designed to address two important questions that arise from the finding of larger IOR following forget than following remember instructions: (a) Why is IOR larger following forget versus remember instructions? and (b) What are the implications of this forget $>$ remember IOR difference? The former question will be addressed in Experiments 1, 2, 3, 4 and 5, and the latter will be addressed in Experiments 6-7.

\section{Experiment 1}

The view that the forget $>$ remember difference in the IOR effect occurs because attention is withdrawn more readily from peripheral words following a forget than following a remember instruction raises the question of whether the memory instruction affects the exogenous and/or endogenous attentional system. Whereas the exogenous attentional system is responsible for the reflexive allocation of attentional resources, the endogenous attentional system is responsible for the voluntary allocation of attentional resources. Importantly, the exogenous and endogenous attentional systems do not simply reflect different mechanisms for allocating a common pool of attentional resources. Instead, they appear to be two attentional systems (Briand \& Klein, 1987) with distinct underlying neural architectures (Posner, 1992; see Corbetta \& Shulman, 2002, for a review).

In Taylor (2005), the memory instruction was a high- or low-frequency tone. Experiment 1 of the present study replicated the methods of Taylor (2005, Exp. 1), except that the memory instruction was a visual onset at center; the results will be compared directly to those of Taylor. We 
reasoned that if the forget $>$ remember difference in IOR magnitude is due to differences in the withdrawal of endogenous attention, this modulation of endogenous attention by the memory instruction should continue to occur, despite the capture of exogenous attention by the abrupt visual onset at the center of the screen. In contrast, if the forget $>$ remember difference in IOR is due to differences in the withdrawal of exogenous attention, the tendency for an abrupt onset to capture exogenous attention automatically should equate exogenous withdrawal in both the forget and remember conditions, and thereby should eliminate the difference in IOR magnitude. To reduce the memory load associated with their interpretation, the visual stimuli used as memory instructions were chosen to map easily onto the instructions: A green " + " served as the remember instruction, and a red " $\times$ " served as the forget instruction.

Method

\section{Participants}

A total of 36 undergraduate students volunteered in exchange for psychology class credit.

\section{Stimuli and apparatus}

Stimulus presentation and data collection were controlled by a Macintosh G4-400 running PsyScope 1.5.2 (Cohen, MacWhinney, Flatt, \& Provost, 1993). The stimuli were presented in a uniform white field on a 17-in. ViewSonic PT775 or an Apple Studio color display monitor; responses were collected using the standard Apple Universal Serial Bus keyboard.

Three stimulus boxes were aligned horizontally across the computer monitor, with the middle box at center. Each box was outlined in black with a 2-point line thickness and, at a viewing distance of $57 \mathrm{~cm}$, were $3^{\circ}$ of visual angle on each side. Measured between adjacent sides, the peripheral boxes were separated from the middle box by $3^{\circ}$ of visual angle.

Two lists of 100 two- to eight-letter nouns were constructed from the Kučera and Francis (1967) word norms. One list was used as a word list for the study trials, and the other was reserved as a foil list for the recognition test. Designation of the word and foil lists was counterbalanced across participants.

The fixation stimulus was a black, solid circle, $0.5^{\circ}$ of visual angle in diameter, centered in the middle stimulus box. The memory instruction was a change in this stimulus to a green "+" (remember) or a red " $\times$ " (forget). The threepoint line segments that comprised both of these stimuli extended $2^{\circ}$ of visual angle and crossed in the center of the middle stimulus box. The target stimulus was a solid black circle-identical to the fixation stimulus - that occurred in the left or right stimulus box.

\section{Procedure}

To maintain equivalence between our methods and those used by Taylor (2005, Exp. 1), we alternated five blocks of 20 study trials with five recall tests, before administering a final recognition test. Participants were given verbal instructions from the experimenter, which were reiterated by written instructions presented on the computer screen prior to beginning the first block of trials. The instructions explained the nonpredictive relation between word location and target location and emphasized the need to respond as quickly and accurately as possible.

Study trials The trial events are depicted in Fig. 1. Each study trial began with the presentation of the three stimulus boxes arranged horizontally across the center of the computer screen. After $500 \mathrm{~ms}$, the fixation stimulus was presented for $800 \mathrm{~ms}$ in the middle box. This was followed by the $400-\mathrm{ms}$ presentation of a word that occurred with equal probability in the center of the left or right

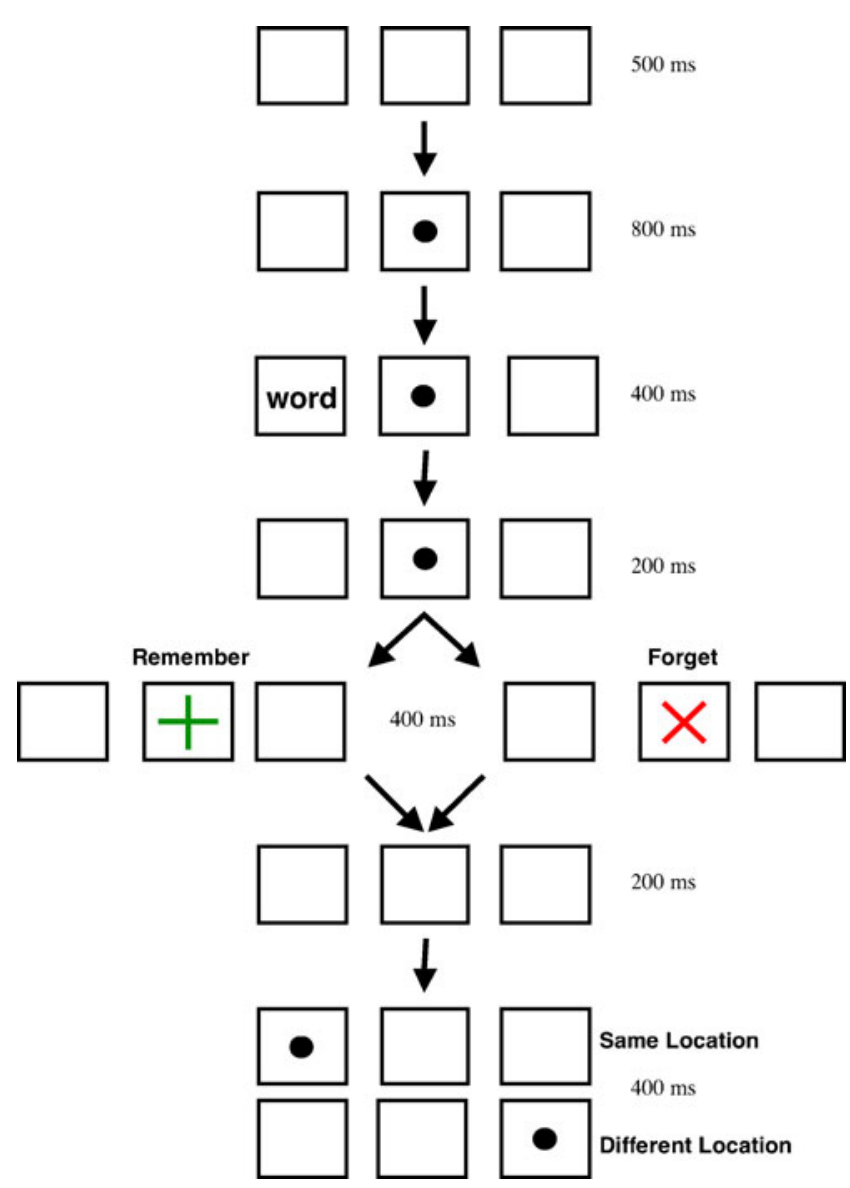

Fig. 1 Stimulus sequence used in the study phase of Experiment 1 
stimulus box; the word was drawn randomly without replacement from the 100-item word list and presented in black, 24-point, all-lowercase letters. No overt response was required to the word. After a 200-ms delay, the memory instruction replaced the fixation stimulus in the middle box and was presented for $400 \mathrm{~ms}$. A random half of the memory instructions were to remember the word that had just been presented; the other half were to forget the word. Following a 200-ms delay, during which time no stimulus was presented in the middle box, a target dot was presented with equal probability in the left or the right stimulus box.

Participants made a speeded spatially compatible response to localize the target, by pressing the "f" key for "left" and the "j" key for "right." Participants heard distinctive auditory feedback following correct responses made within $1,000 \mathrm{~ms}$ of target presentation, incorrect keypresses made to the target, and extraneous keypresses made between the presentation of the word and the target.

Trials were drawn randomly without replacement from the factorial combination of word location (left, right), memory instruction (remember, forget), and target location (left, right) such that each block of trials had a slightly different composition. Given the relatively small number of remember items within a block, we wanted to ensure that participants could not perfectly predict the number they would be required to commit to memory (average $=10$ ). For the purpose of analysis, we collapsed over the same word-target location (left-left, right-right) and different word-target locations (left-right, right-left).

Recall tests Following the presentation of each block of study trials, a recall test was presented. At the beginning of each recall test, instructions at the top of the monitor instructed participants to input the words that they had been asked to remember in the most recent study block. These instructions remained visible throughout the recall trials, along with a prompt to enter a word. Across the horizontal midline of the computer screen was a 6-point outline black box in which keystrokes were made visible to the participant in 18-point Arial Black font. The contents of this box were recorded and then cleared when the space bar was depressed. Words could be entered in upper, lower, or mixed case, but misspelled words were counted as off-list intrusions. As will be seen in the results, there were very few such intrusions/misspellings. The first instance of any duplicated word was accepted; the remaining duplicates were ignored and counted as neither correct productions nor errors.

When participants were finished entering all of the words that they could recall, they pressed an escape sequence to exit the recall test. The study then progressed to the next block of 20 study trials or, following the last recall test, to the recognition test.
Recognition test Following the fifth alternation of study trials with a recall test, participants viewed a computer display that included instructions for a yes-no recognition test. Participants were told to press " $y$ " to any word that had been presented in the study trials - regardless of memory instruction - and " $n$ " to any word that had not been. These instructions remained in the top half of the computer screen, while the word being queried was presented in blue 18-point Arial font in a position located just above a 6-point black outline box that was centered in the middle of the computer screen and used to display the characters entered from the keyboard. In this recognition test, 200 words were presented, which were drawn randomly without replacement from the 100-item word list and the 100-item foil list. Once the space bar was pressed, the entry was recorded and the box cleared of its contents. This task was self-paced.

\section{Results}

Unless otherwise stated, significance for all statistical tests reported in this study was evaluated at the $\alpha=.05$ level; all planned comparisons used the error term from the relevant main effect or interaction. Target RTs were the primary dependent measure of interest. Nevertheless, the recall and recognition tests were examined first to confirm compliance with the memory instructions.

\section{Recall performance}

Recall performance was totaled over the five recall blocks, and the percent correct was calculated out of a total of 50 remember words and 50 forget words. Participants reported an average of $53 \%$ of the remember words and intruded only $3 \%$ of the forget words. This difference was significant, $F(1,35)=249.54, M S E=183.56, p<.01$.

Even though participants were instructed to recall only those words from the most recently presented block of IOR trials, they very occasionally produced intrusions from previous blocks. Averaged over participants, the total number of on-list intrusions was 1.19 ( $S E=0.42)$ remember and $1.28(S E=0.56)$ forget words. This difference was not significant, $F<1$. The average number of off-list intrusions (i.e., the report of words never presented and/or misspellings of presented words) was also small, at $2.83(S E=0.37)$ totaled across five blocks of recall.

\section{Recognition}

The percentages of " $y$ " responses made on the recognition test were $74 \%(S E=3 \%)$ for remember words, $39 \%$ ( $S E=$ $4 \%)$ for forget words, and $14 \%(S E=1 \%)$ for foil words. 
An ANOVA of these data revealed a significant effect of word type, $F(2,70)=179.66, M S E=180.01, p<.01$. Planned comparisons revealed a significant directed forgetting effect, with more "y" responses to remember than to forget words, $F(1,70)=123.76, p<.01$; to remember words than to foils, $F(1,70)=355.37, p<.01$; and to forget words than to foils, $F(1,70)=59.70, p<.01$.

\section{Target reaction times}

Only RTs from trials on which a correct response was made within $80-1,000 \mathrm{~ms}$ of target presentation were analyzed. RTs outside of this response window, incorrect keypresses, or multiple simultaneous or sequential keypresses were counted as errors and excluded. RTs for included trials are shown in Fig. 2, along with their associated percent accuracies.

The RT data were analyzed using a repeated measures ANOVA, with Memory Instruction (remember, forget) and Word-Target Location (same, different) as factors. This analysis revealed a significant main effect of memory instruction, $F(1,35)=18.86, M S E=1,737.28, p<.01$, with overall faster RTs on forget, $M=366 \mathrm{~ms}(S E=8 \mathrm{~ms})$, than on remember, $M=396 \mathrm{~ms}(S E=10 \mathrm{~ms})$, trials. There was also a main effect of word-target location, $F(1,35)=$ 20.09, $M S E=1,455.49, p<.01$, confirming a significant overall 29-ms IOR effect. The interaction of memory instruction and word-target location did not even approach significance, $F<1$. Planned contrasts revealed a significant 32-ms IOR effect on forget trials, $F(1,35)=42.54, p<.01$, and a significant 26-ms IOR effect on remember trials, $F(1,35)=28.91, p<.01$.

An analogous ANOVA of percent accuracy on the target task revealed nonsignificant main effects, both $F_{\mathrm{S}}<1$, and a nonsignificant interaction, $F(1,35)=1.04, M S E=17.05$, $p>.31$.

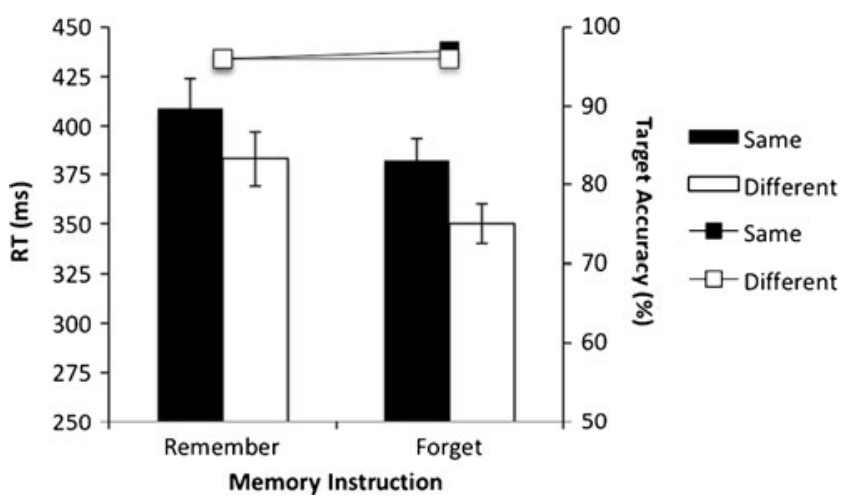

Fig. 2 Experiment 1 results. Reaction times (left $y$-axis) and associated accuracies (right $y$-axis) for the target localization response, as a function of memory instruction (remember, forget) and wordtarget location (same, different). Error bars depict the standard errors of the means; in some cases, they are too small to be visible

\section{Discussion}

The few intrusions of forget items into the immediate free recall tests and the greater recognition of remember than of forget words suggested compliance with the memory instructions. Even so, there was no significant influence of the memory instruction on the magnitude of the IOR effect. These key findings are summarized in Table 1, along with those of subsequent experiments.

To get a baseline measure of the IOR effect, we ran 21 new participants in a replication of Experiment 1 that eliminated the memory component. Everything in the study was identical to Experiment 1, except that the participants were instructed that they were in a control condition and could ignore the words, the green " + " and red " $x$ " had no meaning, and no recall or recognition tests were presented. An ANOVA on the mean RTs for correct trials revealed a significant 27-ms IOR effect, $F(1,20)=40.32, M S E=$ $193.78, p<.01$. The mean RTs were $335 \mathrm{~ms}(S E=9 \mathrm{~ms})$ when targets occurred in the same location as the preceding word and $308 \mathrm{~ms}(S E=6 \mathrm{~ms})$ when targets occurred in a different location. Mean accuracies were high and identical for targets in the same and in the different location relative to the word, $M=98 \%(S E=1 \%), F<1$.

When RTs from this no-memory control condition were compared to the no-memory control condition of Taylor (2005, Exp. 2), there was no significant main effect of experiment, $F(1,35)=2.11, M S E=2,333.98, p>.15$, and no significant interaction of experiment with word-target location, $F<1$. This indicates that in the absence of a concurrent memory task, there was no significant effect on IOR of presenting a visual reorienting event at center $(27 \mathrm{~ms})$ versus presenting a nonorienting tone (22 ms; Taylor, 2005, Exp. 2). There was, however, an effect of the current exogenous reorienting event when the peripheral cue words were subject to remember and forget instructions. An ANOVA that included the factor Experiment (our Exp. 1 vs. Taylor, 2005, Exp. 1) was performed on the target RTs obtained during the performance of the item-method directed forgetting task. There was a main effect of experiment, with overall faster RTs in the present Experiment 1 than in Taylor (2005, Exp. 1), $F(1,49)=8.66, M S E=20,381.66$, $p<.01$. Critically, there was also a three-way interaction of experiment, memory instruction, and word-target location, $F(1,49)=7.28, M S E=562.08, p<.01$. This confirms that the presentation of an exogenous reorienting event in the present study eliminated the forget $>$ remember IOR difference that was obtained by Taylor (2005, Exp. 1) using a nonorienting tone as the memory instruction. This finding is predicted by the view that the forget $>$ remember IOR difference is due to differential withdrawal of exogenousrather than endogenous - attention. No other effects that included the Experiment factor were significant, all $p \mathrm{~s}>.18$. 
Table 1 Summary of the key findings for Experiments 1-7

\begin{tabular}{|c|c|c|c|c|}
\hline Exp. & Description & Response & DFE $(\%)$ & $\mathrm{F}>\mathrm{R}$ IOR $(\mathrm{ms})$ \\
\hline 1 & Visual instruction at center - recall tests administered throughout study & Localization & $35^{*}$ & 6 \\
\hline 2 & Auditory instruction & Localization & $12^{*}$ & $21^{*}$ \\
\hline 3 & Auditory instruction, targets $60 \%$ likely at center & Localization & $28^{*}$ & $29^{*}$ \\
\hline 4 & Auditory instruction, fixed word-target SOA, variable instruction-target SOA & Localization & $23^{*}$ & $24^{*}$ \\
\hline 5 & Auditory instruction followed by visual onset at center & Localization & $15^{*}$ & 9 \\
\hline 6 & Auditory instruction, variable instruction-target SOA & Detection & $20^{*}$ & -6 \\
\hline 7 & Auditory instruction, variable instruction-target SOA & Discrimination & $30^{*}$ & -6 \\
\hline
\end{tabular}

DFE, directed forgetting effect, calculated by subtracting the percentage of recognized forget $(F)$ words from the percentage of recognized remember (R) words. F $>$ R IOR, the difference in the magnitude of IOR observed following forget and remember instructions. An asterisk $\left({ }^{*}\right)$ signifies a significant effect, $p<.05$.

The fact that the exogenous rather than the endogenous attentional system is differentially engaged by the intention to remember or to forget may seem somewhat surprising. One might have expected that the intentional, top-down nature of directed forgetting would engage the top-down voluntary control of the endogenous attentional system. The fact that it does not suggests that any differential withdrawal of attention following the memory instruction occurs automatically and not volitionally. That is, participants do not purposefully withdraw attention as a means of instantiating the memory instruction; instead, any effect on attention is elicited automatically by the intention to remember or forget. This relationship between the intention to remember or forget and the withdrawal of attention will be explored more fully in the General Discussion.

The remaining experiments presented tones as memory instructions, to avoid the capture of exogenous attention back to center. Also, the recall tests were eliminated (see also Taylor, 2005, Exp. 3) such that compliance with the memory instructions was assessed via recognition alone.

\section{Experiment 2}

The results of Experiment 1 suggest that obtaining a forget $>$ remember IOR difference requires the opportunity for exogenous attention to be modulated by the memory instruction: When an onset is presented at center, thereby equating exogenous withdrawal for both the forget and remember conditions, the IOR difference does not occur. However, the fact that the onset at center was an informative memory instruction leaves open the possibility that the forget $>$ remember IOR difference was absent because the withdrawal of endogenous - rather than exogenous-attention was equated by the need to interpret the central instruction. To address this, in Experiment 2 we explicitly manipulated endogenous attention by presenting $60 \%$ of all localization targets at center (e.g., Posner \& Cohen, 1984). This was intended to draw endogenous attention to the center in accordance with the target probabilities, while leaving exogenous attention susceptible to modulation by the memory instruction. If the forget $>$ remember IOR difference is due to modulation of exogenous attention, as we have surmised from Experiment 1, a forget $>$ remember difference should be obtained in Experiment 2.

\section{Method}

\section{Participants}

A total of 32 undergraduate students enrolled in an Introduction to Psychology course volunteered to participate in exchange for course credit.

\section{Stimuli and apparatus}

The stimuli and apparatus were identical to those in Experiment 1, with the following exceptions.

The memory instruction was a high-frequency $(1170-\mathrm{Hz})$ or low-frequency $(260-\mathrm{Hz})$ tone played simultaneously to both ears, using Sony MDR-XD100 headphones. The assignment of high- and low-frequency tones to remember and forget instructions was counterbalanced across participants. To distinguish the fixation stimulus from central targets, a 24-point black "+" served as the fixation stimulus.

An online list generator (www.math.yorku.ca/SCS/ Online/paivio/) was used to create two lists of 160 words each. The two lists were matched on Kučera-Francis word frequencies (cf. Kučera \& Francis, 1967; $M=180$ vs. 232, $p>.11$ ), average number of letters (both $M \mathrm{~s}=5.1, t<1$ ), concreteness $(M=375$ vs. $370, p>.51)$, number of syllables (both $M \mathrm{~s}=1.5, t<1$ ), and range of word length (both $R \mathrm{~s}=3-7$ letters). One list was used as study words, and the other was used as foil words; the designation of lists as study and foil was counterbalanced across partic- 
ipants within each tone designation. In addition, a list of five "buffer" words (dog, pencil, farmer, floss, printer) was used for all participants (see below).

\section{Procedure}

Prior to beginning the experimental block, participants were given practice with the target localization task (with $60 \%$ of the targets at center). In these practice trials, the stimulus and timing parameters were identical to those in the experimental study trials, except that word was presented in place of a study word, the memory instruction had no meaning, and no recognition test was administered. Participants ran in approximately 20 practice trials; the RT data from those trials were neither saved nor analyzed.

At the start of the experiment proper, the experimenter provided a verbal description of the experiment that was reiterated by on-screen instructions. Participants were instructed to respond as quickly and as accurately as possible by depressing the "f" key with the left index finger when targets appeared on the left, the " $\mathrm{j}$ " key with the right index finger when targets appeared on the right, and the space bar with both thumbs when the target appeared in the center. Participants were explicitly informed that the majority of targets $(60 \%)$ would occur at center and that a minority would appear to the left $(20 \%)$ and the right $(20 \%)$; the lack of a predictive relationship between word location and target location was described. Participants were informed that a recognition memory test would be administered following the study trials, but no mention was made of the fact that memory would be tested for all study words.

After a participant had received the instructions, the experimenter left the room and the participant was presented with 10 tone familiarization trials. These trials were intended to acquaint the participant with the sound of the tones and to reinforce their meaning as memory instructions. In a random half of the tone familiarization trials, a high tone was presented; in the other half, a low tone was presented. For $3 \mathrm{~s}$, the relevant tone-instruction pairing was described by words in the center of the screen (e.g., "high tone - remember"); $2 \mathrm{~s}$ into this visual presentation, the corresponding tone sounded; no response was required.

Following the tone familiarization trials, participants were prompted to press the space bar to begin the study trials.

Study trials Five buffer trials were presented at the start of the study block. In these buffer trials, a word was drawn randomly from the five-item buffer list and a remember instruction was always presented. RTs to targets on the buffer trials were not analyzed, and recognition of the buffer words was not tested.

Following the buffer trials, the study trials were presented. The stimulus and timing parameters of these trials were identical to those in Experiment 1, except that a high- or low-frequency tone served as the memory instruction. The fixation stimulus ("+") remained visible until the end of the trial, except when temporarily overwritten by the presentation of a central target. If participants made a correct response to the target within $1,000 \mathrm{~ms}$ of target onset, this fixation stimulus changed from black to green font for $500 \mathrm{~ms}$.

There were 160 study trials, corresponding to a withinsubjects mixed-blocks factorial design consisting of 8 repetitions of a 2 (word location: left, right) $\times 2$ (memory instruction: remember, forget) $\times 2$ (target location: left, right) and 24 repetitions of a 2 (word location: left, right) $\times 2$ (memory instruction: remember, forget) $\times 1$ (target location: center) design. The study trials were presented in a single block with no breaks. For the purpose of analysis, peripheral targets were collapsed according to whether they occurred in the same or a different location relative to the peripheral word.

Recognition test The recognition test was the same as described for Experiment 1, except that 320 trials were presented ( 80 remember words, 80 forget words, and 160 foils).

\section{Results}

The data from 3 participants were eliminated due to average target errors and/or RTs that exceeded the overall mean by at least two standard deviations.

\section{Recognition}

The percentages of " $y$ " responses made on the recognition test were $49 \%(S E=3 \%)$ for remember words, $37 \%(S E=$ $3 \%)$ for forget words, and $24 \%(S E=3 \%)$ for foil words. An ANOVA of these data revealed a significant effect of word type, $F(2,56)=54.68, M S E=83.12, p<.01$. Planned comparisons revealed a significant directed forgetting effect, with more hits ("y" responses) to remember than to forget words, $F(1,56)=28.06, p<.01$. Relative to foil words, there were also significantly more "y" responses to remember words, $F(1,56)=109.35, p<.01$, and to forget words, $F(1,56)=25.62, p<.01$.

\section{Target reaction times}

Trials on which participants failed to respond correctly within $80-1,000 \mathrm{~ms}$ of target onset or else made an incorrect keypress or multiple keypresses were considered errors and excluded from the RT analysis. The mean RTs for the included trials are shown in Fig. 3, along with their associated accuracies. 


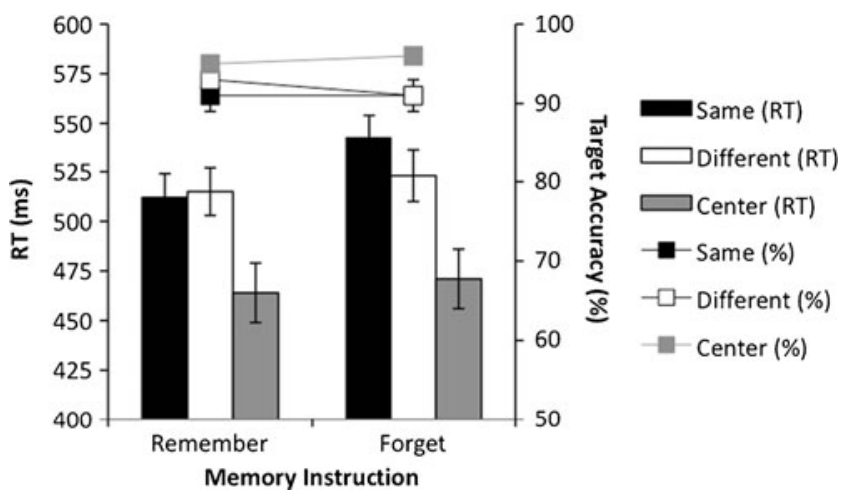

Fig. 3 Experiment 2 results. Reaction times (left $y$-axis) and associated accuracies (right $y$-axis) for the target localization response, as a function of memory instruction (remember, forget) and target location (same, different, center). Error bars depict the standard errors of the means; in some cases, they are too small to be visible

The RT data were analyzed using a repeated measures ANOVA, with memory instruction (remember, forget) and target location (same, different, center) as factors. This analysis revealed a significant main effect of memory instruction, $F(1,28)=10.32, M S E=969.45, p<.01$, with overall slower RTs following a forget instruction, $M=$ $512 \mathrm{~ms}(S E=8 \mathrm{~ms})$, than following a remember instruction, $M=497 \mathrm{~ms}(S E=8 \mathrm{~ms})$. There was also a significant effect of target location, $F(2,56)=26.30$, $M S E=2,275.84, p<.01$, with overall faster RTs to targets at the center location, $M=468 \mathrm{~ms}(S E=10 \mathrm{~ms})$, than to targets that appeared at the same peripheral location as the word, $M=527 \mathrm{~ms}(S E=8 \mathrm{~ms})$, or at a different peripheral location, $M=519 \mathrm{~ms}(S E=9 \mathrm{~ms})$. Critically, these two main effects were qualified by a significant interaction between memory instruction and target location, $F(2,56)=3.33, M S E=736.18, p<.05$. As can be seen in Fig. 3, this interaction stemmed from IOR effects of different magnitudes in the forget and remember conditions. More particularly, there was a significant 18-ms IOR effect following a forget instruction, $F(1,56)=6.53, p<.02$, and a nonsignificant 3 -ms facilitatory effect following a remember instruction, $F<1$. Importantly, this difference occurred in the context of fastest overall RTs to targets that occurred at the most likelycenter-location; these RTs did not differ significantly on forget and remember trials, $F<1$.

An analogous ANOVA was performed on the percent accuracies (shown in Fig. 3). This analysis revealed a significant main effect of target location, $F(2,56)=7.09$, $M S E=45.99, p<.01$. This was due to overall higher accuracy to targets that appeared in the center location, $M=95 \%(S E=1 \%)$, compared to those that appeared in the same, $M=91 \%(S E=1 \%)$, or different, $M=92 \%(S E=$ $1 \%$ ), location relative to the word. No other effects were significant, $F \mathrm{~s}<1$.

\section{Discussion}

The recognition test of Experiment 2 revealed a standard directed forgetting effect when a tone was used as a memory instruction (see also Taylor, 2005). Localization targets occurred at center $60 \%$ of the time, and to the left or right of center only $20 \%$ of the time apiece, thereby encouraging the allocation of endogenous attention to the center location. The effectiveness of this probability manipulation is suggested by the overall faster RTs to targets at the uncued center location, as compared to an uncued peripheral location (cf. Posner \& Cohen, 1984; although see Bartolomeo, Decaix, \& Siéroff, 2007, and Risko \& Stoltz, 2010, for alternative interpretations). Importantly, the speed to respond to these uncued center targets was not significantly different following remember and forget trials. This argues that the probability manipulation was as effective at allocating covert and/or overt attention on forget trials as on remember trials. Nevertheless, a forget $>$ remember IOR difference was obtained. This suggests, consistent with the conclusions of Experiment 1, that the forget $>$ remember difference in IOR is tied to the differential withdrawal of exogenous attention: The difference disappears when exogenous attention is equated on remember and forget trials by attracting attention to center by an onset event (Exp. 1) but appears when endogenous attention is allocated to center on both types of trial in accordance with high target probabilities (Exp. 2).

\section{Experiment 3}

Experiments 1 and 2 suggest that there is a forget $>$ remember IOR difference when exogenous attention is free to be differentially allocated following the memory instruction. However, IOR effects are of limited temporal duration (see, e.g., Samuel \& Kat, 2003). As such, it is possible that the IOR effect that would normally develop over the given word-target SOA could have its time course-rather than its magnitude - shifted by the intervening remember and forget instructions. Consider, for example, if an IOR effect of otherwise equivalent magnitude developed and then dissipated more quickly following a remember than following a forget instruction. This could account for a greater-magnitude IOR effect for forget than for remember trials at a given instruction-target interval-not because forget and remember instructions lead to a differential withdrawal of exogenous attentional resources from the representation of the peripherally presented word, but because these instructions lead to a different time course in the development of an otherwise equivalent withdrawal of resources. To test this, in Experiment 3 we held the word-target SOA constant at 1,200 ms-the same as used by Taylor (2005) and Experiments 1 and 2-and 
varied the temporal placement of the intervening memory instruction. Thus, the time between the onset of the word used to generate IOR and the onset of the target used to measure IOR did not vary. Instead, what varied was the amount of time available for the memory instruction to influence responses to the subsequent localization target.

Note that the timing of the instruction was manipulated because the instruction to remember or forget is what modulates the magnitude of IOR that is otherwise generated by the peripherally presented word and measured by the target RTs. Because the word-target interval remained fixed, the variable placement of the intervening memory instruction necessarily produced complementary variations in the word-instruction and instruction-target SOAs. For the sake of presentation, the SOA manipulation will be described in terms of instruction-target SOA, given that the instruction is responsible for forget-remember differences in target RTs. The instruction-target SOAs were 400, 500, 600, 700, and $800 \mathrm{~ms}$.

\section{Method}

\section{Participants}

A total of 24 undergraduate students enrolled in an Introduction to Psychology course volunteered to participate in exchange for course credit.

\section{Stimuli and apparatus}

The stimuli and apparatus were identical to those of Experiment 2, with the following exceptions. Targets were presented with equal probability to the left and right; there were no target presentations at center. Instead, a fixation stimulus like that described for Experiment 1 remained visible in the center box throughout the trial. Feedback was given for correct responses to the target task via a change in the fill of the fixation stimulus from black to green; error feedback was given by computer-generated auditory signals.

An online list generator (www.math.yorku.ca/SCS/Online/ paivio/) was used to create two lists containing 180 and 160 words, respectively. ${ }^{1}$ The two lists were matched on Kučera-

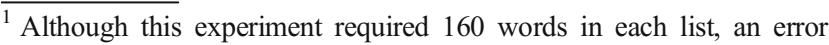
resulted in one of the lists containing an extra 20 words (for a total of 180 words). When this list was designated as the foil list, the longer length was not a problem: It did not matter which 160 of the 180 unstudied items were presented. When the longer list was designated as the "study" list - as it was for half of the participants - 160 items were drawn randomly for presentation, as was intended. At recognition, however, it was possible for up to 20 unstudied items from this list to be randomly drawn and presented on trials that were intended to present studied items. When this happened, these trials were excluded from analysis altogether. We compared the recognition performance of those participants for whom the long list served as the study list and those for whom it served as the foil list; there were no significant differences.
}

Francis word frequencies (cf. Kučera \& Francis, 1967; $M=$ 42 vs. $45, p>.41)$, average number of letters $(M=5.6$ vs. $5.5, p>.39$ ), imagery (both $M \mathrm{~s}=6, t<1$ ), concreteness (both $M \mathrm{~s}=7, t<1$ ), meaningfulness (both $M \mathrm{~s}=7, t<1$ ), number of syllables (both $M \mathrm{~s}=1.7, t<1$ ), and range of word lengths (both $R \mathrm{~s}=3-8$ letters). One list was used to randomly draw 160 study words, and the other was used to randomly draw 160 foil words; the designation of lists as study and foil was counterbalanced across participants within each tone designation. In addition, a "buffer" list of 5 words was used for all participants.

\section{Procedure}

The procedure was identical to that of Experiment 2, with the following exceptions. Relative to the onset of the peripheral word, the tone that served as the memory instruction occurred with equal probability at $400,500,600,700$, and $800 \mathrm{~ms}$. Given the fixed 1,200-ms word-target interval, these onset times corresponded to instruction-target SOAs of 800 , $700,600,500$, and $400 \mathrm{~ms}$, respectively; the relative timing of stimulus events and the complementary relationship between the word-instruction and instruction-target SOAs are depicted in Fig. 4.

Targets appeared with equal probability to the left and the right. In both the practice trials and the experiment proper, participants used their left and right index fingers to depress the " $\mathrm{f}$ " and " $\mathrm{j}$ " keys, respectively, to make spatially compatible target localization responses.

There were 160 trials, corresponding to 4 repetitions of a 2 (word location: left, right) $\times 2$ (memory instruction: remember, forget) $\times 5$ (instruction-target SOA: 400, 500, $600,700,800 \mathrm{~ms}) \times 2$ (target location: left, right) withinsubjects mixed-blocks factorial design. For the purpose of analysis, word and target locations were collapsed into a single factor (word-target location: same, different).

\section{Results}

The data from 2 participants were excluded from analysis due to target errors that exceeded two standard deviations above the mean of all participants.

\section{Recognition}

The percentages of " $y$ " responses made on the recognition test were $61 \%(S E=3 \%)$ for remember words, 33\% (SE = $4 \%)$ for forget words, and $12 \%(S E=2 \%)$ for foil words. An ANOVA of these data revealed a significant effect of word type, $F(2,42)=121.14, M S E=108.57, p<.01$. Planned comparisons revealed a significant directed forgetting effect, with more " $y$ " responses to remember than to forget words, $F(1,42)=76.70, p<.01$. Relative to foil 
Fig. 4 Timing parameters for study trial events in Experiment 3

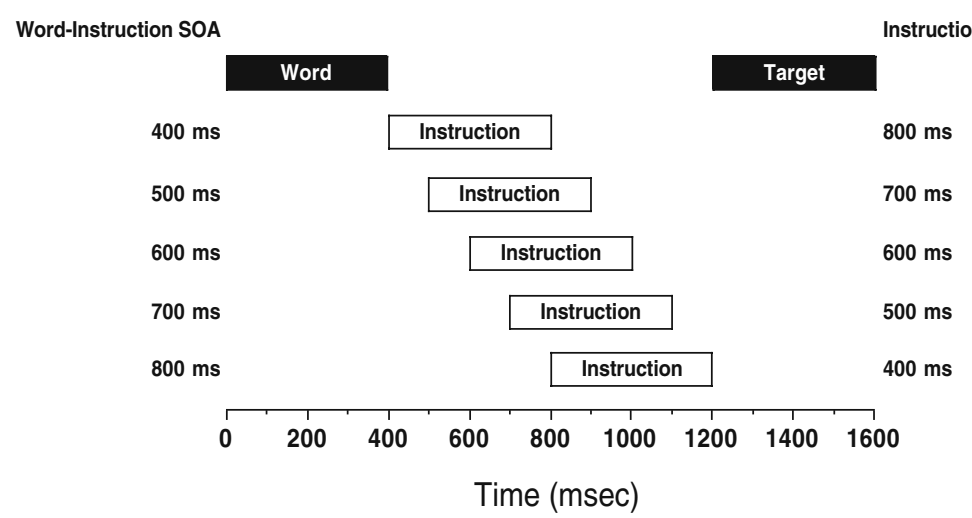

SOA, and word-target location was not significant, $F(4,84)=1.63, M S E=1,094.08, p>.17$, indicating that the forget $>$ remember difference did not vary significantly as a function of instruction-target SOA.

The percent accuracy data for the target task were analyzed in an analogous ANOVA. The only effect to approach significance was the two-way interaction of memory instruction and word-target location, $F(1,21)=4.05, M S E=42.41$, $p=.06$. On remember trials, responses were $1 \%$ more accurate when targets occurred in the same rather than in a different location relative to the word; on forget trials, responses were $1 \%$ less accurate when targets occurred in the same rather than in a different location relative to the word.

\section{Discussion}

The significant directed forgetting effect observed in Experiment 3 confirmed that remember and forget instructions had the expected effect on recognition performance. This being the case, the critical question was whether an otherwise equivalent-magnitude IOR effect emerged and dissipated on a different timecourse following forget and remember instructions. It did not. The forget $>$ remember IOR difference occurred across a wide range of instructiontarget SOAs and did not vary significantly with SOA. This suggests that when words in an item-method directed forgetting paradigm serve as spatially unpredictive onset cues in the periphery, the forget $>$ remember IOR difference reflects a more complete withdrawal of attention from forget than from remember words and not a different time course for otherwise equivalent withdrawal.

At first blush, the lack of an evident time course may seem surprising. However, there was no opportunity for the time course of an overall IOR effect to develop. This is because the interval between the onset of the stimulus used to generate the IOR effect (i.e., the peripheral word) and that used to measure its consequences (i.e., the target) was fixed at $1,200 \mathrm{~ms}$. The only time course potentially measurable was the modulation of the IOR effect by an intervening memory instruction. Our results clearly reveal
(1, 21) $=34.46, p<01$. The three-n interaction between memory instruction, instruction-target 
Fig. 5 Results for Experiments 3, 4, 6, and 7. Reaction times (left $y$-axis) and associated accuracies (right $y$-axis), as a function of instruction-target SOA, memory instruction (remember, left panels; forget, right panels), and target location (same, different).

(a) Experiment 3: Target

localization with a fixed word-target SOA. (b)

Experiment 4: Target localization with a fixed word-instruction SOA. (c) Experiment 6: Target detection. (d) Experiment 7: Target discrimination. Error bars depict the standard errors of the means; in some cases, they are too small to be visible

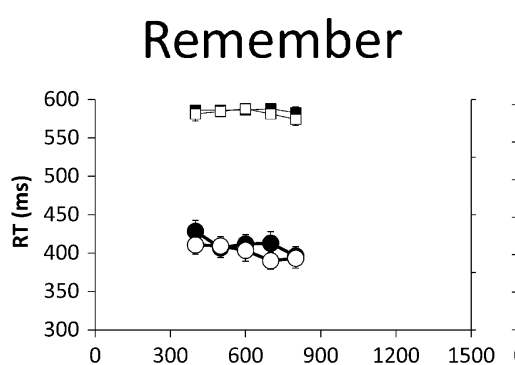

Forget

a) Experiment 3 Localization Fixed Word-Target SOA

b) Experiment 4 Localization Fixed Word-Instruction SOA

C) Experiment 6 Detection

d) Experiment 7 Discrimination
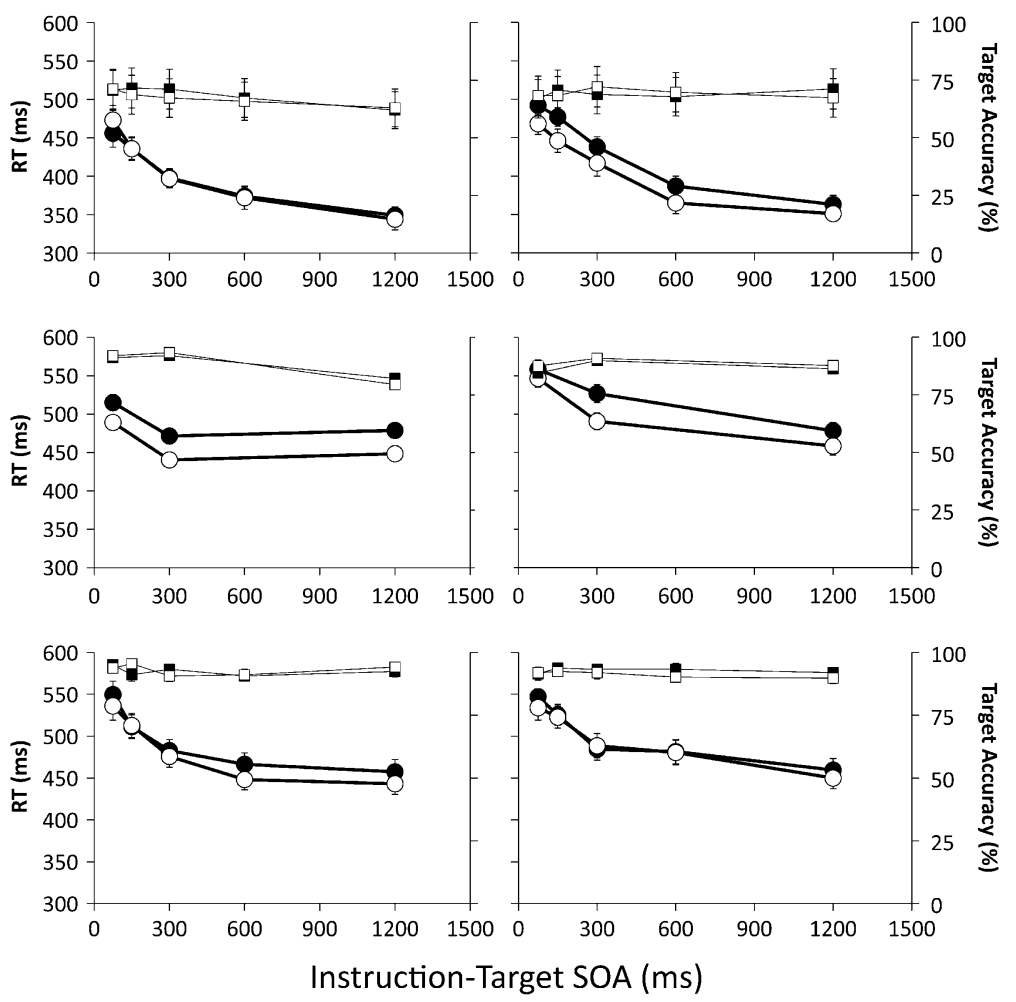

that the memory instruction can modulate the IOR effect across a range of intervals - it does not matter whether the instruction occurs shortly after the word or shortly before the target; as long as the instruction occurs sometime in the 1,200-ms SOA between word and target, IOR will be larger on forget than on remember trials.

On the view that it should take measurable time for the memory instruction to modulate the IOR effect, the condition in which the instruction occurred closest to the target is where one might have expected the smallest forget $>$ remember IOR difference (since there would be the least amount of time available for the instruction to operate prior to target onset). However, this minimal instruction-target SOA was still $400 \mathrm{~ms}$ in the present experiment. And, given the fact that auditory stimuli may be perceived up to $150 \mathrm{~ms}$ more quickly than visual stimuli (see, e.g., Stone et al., 2001), the functional SOA was likely even longer than this. Thus, the timing of our stimuli prohibited a fine-grained time-course analysis for the development of the effect of the instruction on IOR. Nevertheless, we satisfied our purpose by clearly indicating that previous demonstrations of a forget $>$ remember IOR effect (using stimuli of the same duration, a single instruction-target interval, and a fixed 1,200-ms word-target SOA; e.g., Taylor, 2005) were not due to point sampling from different remember and forget time-course functions.

Although it was not a motivated feature of our design, our placement of the memory instruction at various intervals following the word meant that, across trials, there were variable durations of maintenance rehearsal. The word-instruction SOA varied from a low of $400 \mathrm{~ms}$ to a high of $800 \mathrm{~ms}$, in 100-ms increments (see the left $y$-axis of Fig. 4). We analyzed recognition hits in an ANOVA, with memory instruction (remember, forget) and word-instruction SOA (400, 500, 600, 700, $800 \mathrm{~ms})$ as within-subjects variables. There was, of course, a significant main effect of memory instruction, reflecting the overall directed forget- 
ting effect, $F(1,21)=62.72, M S E=593.08, p<.01$. However, supporting the distinction between Type I (maintenance) and Type II (elaborative) rehearsal (see Craik \& Lockhart, 1972; Craik \& Watkins, 1973), we found no significant main effect of rehearsal duration, $F<$ 1. There was also no interaction of memory instruction and rehearsal duration, $F<1$. Indeed, a linear trend analysis revealed no significant change in recognition as a function of rehearsal duration for either remember, $F(1,84)=1.43$, $M S E=163.86, p>.23$, or forget, $F<1$, instructions.

In a control experiment, 24 new participants were exposed to exactly the same methods as in Experiment 3, except that the memory task was eliminated. The RT data revealed no main effect of the meaningless tone stimulus, $F(4,23)=1.25, M S E=575.97, p>.29$, and no effect of this tone stimulus as a function of when it occurred relative to the target, $F<1$. There was only a significant 9 -ms IOR effect, reflected in a main effect of word-target location, $F(1,23)=8.88, M S E=578.77, p<.01$; the RTs were $357 \mathrm{~ms}$ $(S E=5 \mathrm{~ms})$ to targets in the same location as the word and $348 \mathrm{~ms}(S E=5 \mathrm{~ms})$ to targets in a different location. Target accuracies showed no significant effects, all $p \mathrm{~s}>.33$.

Interestingly, the 9-ms IOR effect obtained in our control condition was numerically similar to the 10 -ms IOR effect obtained in the remember condition. It is unlikely that the similarity is due to a tendency for control participants to try to commit the task-irrelevant word cues to memory: A very similar, 10-ms, IOR effect was obtained by Taylor and Therrien (2005) in a task that presented face stimuli as cues in a target localization task (cue-target $\mathrm{SOA}=1,000 \mathrm{~ms}$ ). As with word cues, face stimuli are inherently meaningful; however, the same face stimulus was used trial to trial, and there would have been no reason for participants to commit the item to memory. This suggests that the 9-ms IOR effect obtained in our control condition is a good estimate of the "baseline" IOR effect. To the extent that this is true, it suggests that the forget $>$ remember IOR difference is attributable - in large measure - to a magnification of IOR by a forget instruction rather than by a large reduction in IOR by a remember instruction.

\section{Experiment 4}

In Experiment 3, the word-target interval was held constant while the instruction-target interval varied. This meant that by the time the target was presented, $1,200 \mathrm{~ms}$ had elapsed since the presentation of the peripheral word. As such, the time course of the effects of a memory instruction on target RTs was mapped by varying the timing of the intervening tone. Any effects of the memory instruction were specific to the magnitude of the IOR effect that would otherwise occur at a 1,200-ms word-target SOA. In other words, a fixed window was available for IOR to develop, and the effects of interposing a memory instruction during this window were examined.

In Experiment 4, we instead manipulated the word-target SOA while holding the interval between the word and the instruction constant. On each trial, a word was presented to the left or right. Immediately after its disappearance, participants received an instruction to remember or forget that word. The onset of this instruction was followed by the onset of a target at intervals of $75,150,300,600$, and $1,200 \mathrm{~ms}$. These instruction-target SOAs corresponded to word-target SOAs of 475, 550, 700, 1,000, and 1,600 ms. The purpose of Experiment 4 was to provide converging evidence for the finding that the IOR effect for target localization was larger following an instruction to forget than following an instruction to remember. Given that the effect of memory instruction on target RTs was of primary interest, the following results will be described in terms of instruction-target SOA.

\section{Method}

\section{Participants}

Initially, data were collected from 24 undergraduates who volunteered in exchange for course credit. Due to difficulties in completing the task, 1 of these participants was replaced with a new participant.

\section{Stimuli and apparatus}

The stimuli and apparatus were identical to those described for Experiment 3.

\section{Procedure}

The procedure was the same as in Experiment 3, except that the instruction always occurred immediately after the disappearance of the peripheral word. Relative to the onset of the instruction, the target occurred with equal probability at SOAs of $75,150,300,600$, and $1,200 \mathrm{~ms}$. These timings are depicted in Fig. 6.

Results

The data contributed by 1 participant were eliminated due to target errors that exceeded two standard deviations of the overall mean. The data from the remaining 23 participants were analyzed.

\section{Recognition}

On the recognition test, "y" responses were made to $56 \%$ ( $S E=$ $3 \%)$ of remember words, $33 \%(S E=4 \%)$ of forget words, 
Fig. 6 Timing parameters for study trial events in Experiments 4,6 , and 7

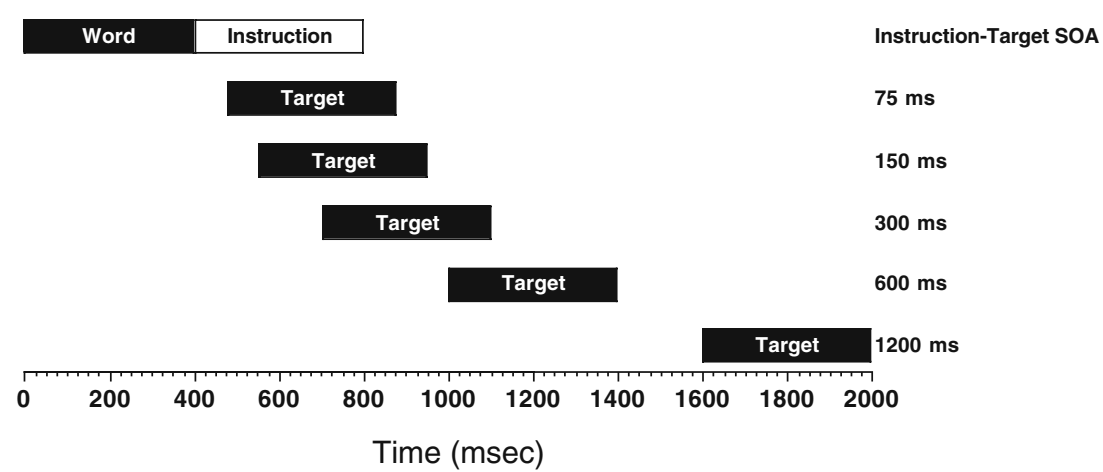

and $11 \%(S E=2 \%)$ of foil words. An ANOVA of these data revealed a significant effect of word type, $F(2,44)=124.73$, $M S E=90.88, p<.01$. Planned comparisons confirmed a significant directed forgetting effect, with more " $y$ " responses to remember than to forget words, $F(1,44)=68.12, p<.01$. Also, relative to foils, there were more " $y$ " responses made to both remember words, $F(1,44)=249.29, p<.01$, and forget words, $F(1,44)=56.78, p<.01$.

\section{Target reaction times}

Trials on which participants failed to make a single correct buttonpress to localize the target within $80-1,000 \mathrm{~ms}$ of its onset were considered errors and eliminated from the analysis of RTs. The correct RT data and their associated accuracies are shown in Fig. 5b.

The RT data were analyzed as a function of memory instruction (remember, forget), instruction-target SOA (75, $150,300,600,1,200 \mathrm{~ms}$ ), and word-target location (same, different). This analysis revealed a significant effect of memory instruction, with overall slower RTs following forget instructions, $M=420 \mathrm{~ms}(S E=5 \mathrm{~ms})$, than following remember instructions, $M=404 \mathrm{~ms}(S E=5 \mathrm{~ms}), F(1,22)=$ 9.36, $M S E=3,444.13, p<.01$. There was also a main effect of SOA, with average RTs decreasing with increasing instruction-target SOA, $F(4,88)=72.28, M S E=3,176.63$, $p<.01$. The main effect of word-target location was not significant, $F(1,22)=2.10, M S E=5,574.23, p>.16$; the average RTs were $417 \mathrm{~ms}(S E=5 \mathrm{~ms})$ for targets in the same location and $407 \mathrm{~ms}(S E=5 \mathrm{~ms})$ for targets in a different location.

Neither the two-way interaction between memory instruction and SOA, $F(4,88)=1.70, M S E=1,669.84, p>.15$, nor the two-way interaction between SOA and word-target location, $F<1$, was significant. There was, however, a significant two-way interaction between memory instruction and word-target location, $F(1,22)=5.51, M S E=2,878.11$, $p<.03$, confirming larger IOR following forget than following remember instructions. Planned comparisons revealed that the 22-ms IOR effect in the forget condition was significant, $F(1,22)=9.52, p<.01$, whereas the $-2-\mathrm{ms}$
IOR effect in the remember condition was not, $F<1$. The three-way interaction of memory instruction, instructiontarget SOA, and word-target location was not significant, $F(4,88)=1.15, M S E=825.71, p>.33$.

Percent accuracies on the target task were analyzed in an analogous ANOVA. The only significant main effect was that of instruction-target $\mathrm{SOA}, F(4,88)=5.54, M S E=$ $66.68, p<.01$; other $p \mathrm{~s}>.17$. The only significant interaction was the three-way interaction of memory instruction, instruction-target SOA, and word-target location, $F(4,88)=2.84, M S E=65.12, p<.03$; all other $p \mathrm{~s}>$ .26. This three-way interaction stemmed from significantly greater accuracy on same than on different trials at the 150$\mathrm{ms}$ SOA in the forget condition (98\% vs. 93\%), $F(1,88)=$ $4.23, p<.05$, and at the $300-\mathrm{ms} \mathrm{SOA}$ in the remember condition (99\% vs. 93\%), $F(1,88)=5.22, p<.03$, and from marginally greater accuracy on same than on different trials at the $1,200-\mathrm{ms} \mathrm{SOA}$ in the forget condition (97\% vs. $92 \%), F(1,88)=3.34, p>.07$; all other $p \mathrm{~s}>.17$.

\section{Discussion}

In Experiment 4, we manipulated instruction-target SOA by fixing the time between the peripheral word and memory instruction and varying the time of the target onset. Despite the change in how instruction-target SOA was manipulated, the results of Experiment 4 were similar to those of Experiment 3: There was a significant directed forgetting effect in recognition, as well as a forget $>$ remember IOR difference that did not vary significantly with SOA. Although this significant forget $>$ remember IOR difference was qualified by a three-way interaction in accuracies at the shortest and longest SOAs, the overall difference-which was maintained across intermediate SOAs - was likely not affected.

As with Experiment 3, the lack of a time-course effect may seem surprising at first - especially in light of the fact that now both the word-target and instruction-target SOAs varied. One might have expected the former to reveal a time course in the development of the overall IOR effect and the latter to reveal a time course in the modulation of this IOR 
effect by the memory instruction. With respect to the former, consider that the word-target SOAs over which IOR was generated and measured ranged from a low of $475 \mathrm{~ms}$ (400-ms word duration $+75-\mathrm{ms}$ delay before the onset of the target in the 75-ms SOA condition; see Fig. 6) to a high of 1,600 ms. In a graphic meta-analysis, Samuel and Kat (2003) demonstrated that the magnitude of the IOR effect is relatively stable between cue-target SOAs of 400-3,000 ms. With our word serving as the peripheral cue in this experiment, it is therefore not surprising that the magnitude of IOR did not vary as a function of increasing word-target SOA. With respect to the instruction-target SOA, our results demonstrate that an auditory instruction can modulate the IOR effect with a "head start" as short as $75 \mathrm{~ms}$ prior to target onset (i.e., the 75-ms SOA condition), with no further gains at increasing instruction-target intervals. That said, however, we again need to distinguish between the nominal and functional SOAs. The shortest nominal SOA between instruction and target was $75 \mathrm{~ms}$. As already noted, auditory stimuli may be perceived up to $150 \mathrm{~ms}$ faster than visual stimuli (Stone et al., 2001), thereby increasing the functional SOA. Thus, our functional SOA may not have been short enough to measure the time course of modulation by the memory instruction. Even so, our results satisfy our purpose by clearly demonstrating that the robust forget $>$ remember IOR differences that we have reported here (Exp. 2) and elsewhere (Taylor, 2005; see also Fawcett \& Taylor, 2010) are not due to point sampling of differing time-course functions for forget and remember trials. Instead, there is a robust forget $>$ remember IOR difference that is relatively constant over a wide range of word-instruction-target intervals.

In a control experiment that eliminated the memory component, localization RTs were obtained from 21 new participants. These data revealed a significant effect of SOA, $F(4,80)=21.11, M S E=417.64, p<.01$, with overall faster RTs with increasing tone-target SOAs. There was also a significant main effect of word-target location, $F(1,20)=10.10, M S E=723.46, p<.01$, with RTs of $362 \mathrm{~ms}(S E=5 \mathrm{~ms})$ for targets that occurred in the same location as the task-irrelevant word and $351 \mathrm{~ms}(S E=5 \mathrm{~ms})$ for targets that occurred in a different location. There was no interaction of tone-target SOA and word-target location, $F<1$. There were no significant effects for target accuracies, all $p \mathrm{~s}>.36$.

The 11-ms IOR effect obtained in the no-memory control condition was numerically in between the $-2-\mathrm{ms}$ IOR effect in the remember condition and the 22-ms IOR effect in the forget condition. Contrary to the results of Experiment 3, this suggests that there may have been a reduction of the IOR effect on remember trials in addition to a magnification of IOR on forget trials. Across all of the experiments that our lab has conducted into the forget $>$ remember IOR difference, we have never found a forget $>$ remember IOR difference that could be accounted for entirely by changes in the remember condition; there is always a magnification of IOR in the forget condition that occurs either alone or - as in this experiment - in tandem with a reduction of IOR in the remember condition. The fact that there is sometimes evidence of attentional dwell in the remember condition in addition to attentional withdrawal in the forget condition behooves us to continue describing the effect in relative terms - as a forget $>$ remember IOR difference.

\section{Experiment 5}

Before considering the implications of the forget $>$ remember IOR difference for subsequent information processing, we wanted to rule out a nonattentional explanation for this difference. In the foregoing, we have argued that the forget $>$ remember IOR difference reflects the differential withdrawal of exogenous attention from peripherally presented forget and remember items. However, a commonality across all of the experiments reported thus far is that the forget $>$ remember IOR difference emerged when the memory instructions were auditory (Exps. 2-4) but not when they were visual (Exp. 1). The goal of Experiment 5 was to present an auditory instruction followed by an irrelevant onset at center. If the modality of the memory instruction is key to finding a forget $>$ remember IOR difference, we should continue to find this difference by virtue of presenting an auditory instruction. If, instead, the forget $>$ remember IOR difference reflects differential withdrawal of exogenous attention from the peripheral word, the central onset should equate the capture of exogenous attention on forget and remember trials, and thereby eliminate any differences in the magnitude of the IOR effect.

\section{Method}

\section{Participants}

Data were collected from 32 undergraduate students who participated in exchange for course credit.

\section{Stimuli and apparatus}

The same 160-item word list used for Experiment 2 was utilized in this experiment. Custom software was used to randomly assign these words to eight study lists of 20 items each and to one foil list of 160 items; a unique randomization was generated for each participant. The green "+" and red " $\times$ " from Experiment 1 were super- 
imposed to create a bicolor asterisk that served as a taskirrelevant onset at center. The stimuli and apparatus were otherwise identical to those of Experiments 2, 3 and 4.

\section{Procedure}

The general procedure was identical to that of Experiment 2 , except that targets occurred only to the left and right (with equal probability), each trial included a task-irrelevant visual onset in the center box, and the fixation stimulus was a solid black circle.

At $800 \mathrm{~ms}$ following the start of each experimental trial, a word appeared for $400 \mathrm{~ms}$ with equal probability to the left and right. Immediately following the disappearance of the word, the high- or low-frequency tone was sounded for $400 \mathrm{~ms}$ and served as the instruction to remember or forget, with the designation counterbalanced across participants. Immediately after the tone, the bicolor asterisk appeared in the center box and remained visible for $400 \mathrm{~ms}$; this stimulus was task irrelevant, required no response, and conveyed no information. After a 200-ms delay, during which all three stimulus boxes remained empty, the target appeared with equal probability to the left or right and remained visible for $400 \mathrm{~ms}$. When participants responded correctly within $1,000 \mathrm{~ms}$ of target onset, a green-filled circle was presented in the middle box for $500 \mathrm{~ms}$. The timings of Experiment 5 ensured that (a) this experiment used the same stimulus durations as previous experiments (i.e., for the word, instruction, onset at fixation, and target); (b) the 600-ms SOA between the central onset event and the target was the same as in Experiment 1 (where the onset had served as the memory instruction); (c) the 400-ms SOA between the onset of the word and the auditory memory instruction was the same that had been used in all conditions of Exp. 4; and (d) the 1,400-ms word-target SOA was within the range shown in Experiment 4 to produce a robust forget $>$ remember IOR difference.

There were 160 trials in the experiment, corresponding to 20 repetitions of a 2 (word location: left, right) $\times 2$ (memory instruction: remember, forget) $\times 2$ (target location: left, right) within-subjects mixed-block factorial design. Each of the eight randomized study lists was uniquely associated with one cell of this design. For the purpose of the analysis, word and target locations were collapsed into a single factor (word-target location: same, different).

Results

\section{Recognition}

During the recognition test, "y" responses were made to $46 \%(S E=3 \%)$ of remember words, $31 \%(S E=3 \%)$ of forget words, and $19 \%(S E=2 \%)$ of foils. A repeated measures ANOVA of these data revealed a significant main effect of word type, $F(2,56)=49.26, M S E=112.22, p<$ .01. Planned comparisons revealed a significant directed forgetting effect, with more recognition hits to remember than to forget words, $F(1,56)=29.76, p<.01$. There were also more "y" responses to remember words than to foils, $F(1,56)=98.18, p<.01$, and to forget words than to foils, $F(1,56)=19.83, p<.01$.

\section{Target reaction times}

Target trials were considered correct if participants made a single response by pressing the correct response key within $80-1,000 \mathrm{~ms}$ of target onset. The RTs for correct target responses were analyzed as a function of memory instruction (remember, forget) and word-target location (same, different). This analysis revealed a significant main effect of memory instruction, $F(1,28)=22.60, M S E=967.04, p<.01$, with overall longer RTs following forget $(M=402 \mathrm{~ms}, S E=8 \mathrm{~ms})$ than following remember $(M=375 \mathrm{~ms}, S E=7 \mathrm{~ms})$ instructions. There was also a significant main effect of target location, $F(1,28)=32.97, M S E=879.23, p<.01$, reflecting an average overall IOR effect of $32 \mathrm{~ms}$. Critically, the twoway interaction of memory instruction and target location did not even approach significance, $F(1,28)=1.45, M S E=$ $433.16, p>.23$. In other words, the significant $27-\mathrm{ms}$ IOR effect in the remember condition, $F(1,28)=24.33, p<.01$, was not significantly different from the also-significant $36-\mathrm{ms}$ IOR effect in the forget condition, $F(1,28)=44.03, p<.01$. Even so, the fact that the magnitude of the IOR effect in the forget condition was numerically larger than in the remember condition led us to conduct a sign test to determine whether there were a significant number of participants who showed a difference in this direction; there were not, $n^{+}=16, n^{-}=13$, $p>.71)$.

The percent accuracies on the target task were analyzed in an analogous ANOVA. This analysis revealed no significant main effect of memory instruction, $F(1,28)=$ 1.66, $M S E=15.48, p>.20$, or of word-target location, $F<$ 1 . There was, however, a significant two-way interaction of memory instruction and word-target location, $F(1,28)=$ 5.78, $M S E=7.31, p<.03$. As can be seen in Fig. 7, this interaction stemmed from overall higher accuracy on same $(M=95 \%, S E=1 \%)$ than on different trials $(M=94 \%, S E=$ $1 \%)$ in the remember condition, and overall lower accuracy on same $(M=93 \%, S E=1 \%)$ than on different trials $(M=$ $94 \%, S E=1 \%)$ in the forget condition. In the remember condition, this pattern was in the direction of a speedaccuracy trade-off, such that accuracy was overall highest in the same condition, where responses were also slowest; importantly, however, this $1 \%$ difference was not statistically significant, $F(1,28)=2.49, p>.12$. In the forget condition, the pattern was opposite a speed-accuracy trade-off, such 


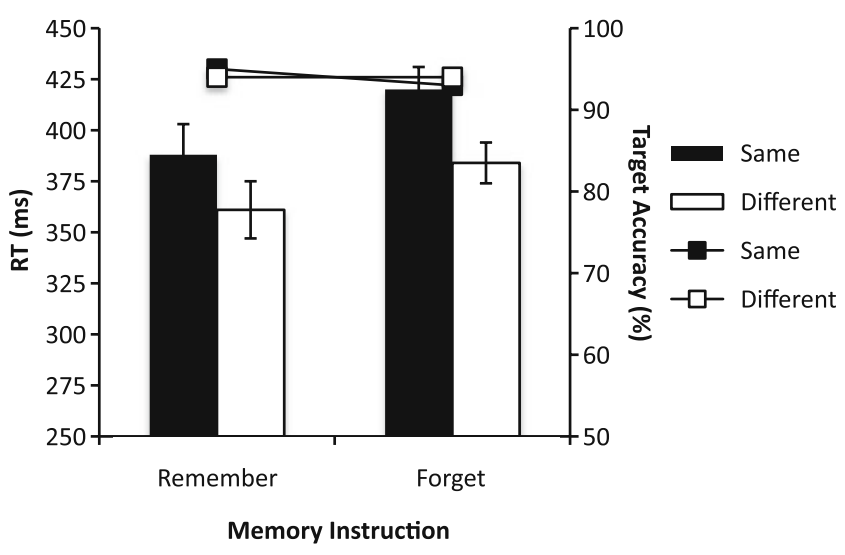

Fig. 7 Experiment 5 results. Reaction times (left $y$-axis) and associated accuracies (right $y$-axis) for the target localization response, as a function of memory instruction (remember, forget) and target location (same, different). Error bars depict the standard errors of the means; in some cases, they are too small to be visible

that accuracy was lowest in the same condition where responses were slowest; the resulting $1 \%$ difference was also not statistically significant, $F(1,28)=3.32, p>.07$.

\section{Discussion}

In Experiment 5, an auditory signal served as the memory instruction and produced the expected directed forgetting effect in recognition. Unlike in Experiments 2-4, however, this auditory memory instruction did not produce a significant forget $>$ remember IOR difference (nor did a significant number of participants show an effect in this direction). This was despite word-instruction and instruction-target intervals that were within the range expected to produce a robust forget $>$ remember IOR difference, based on the time-course data of Experiment 4. If the forget $>$ remember IOR difference were due to instruction modality, the use of an auditory instruction in Experiment 5 should have produced this difference, regardless of the interposition of a task-irrelevant onset at center. This did not happen. Instead, the results of Experiment 5 are consistent with our supposition that the task-irrelevant onset at center eliminated the forget > remember IOR difference by preventing the modulation of exogenous attention by the memory instruction.

\section{Experiment 6}

Whereas Experiments 1-5 addressed the source of the forget $>$ remember IOR difference, Experiments 6 and 7 addressed the implications of this magnitude difference. The fact that the forget $>$ remember IOR difference appears to be caused by the differential withdrawal of exogenous attention does not necessarily mean that attention will be differentially slowed from returning to the location of forget and remember words (see Taylor \& Klein, 1998, for the distinction between the causes and effects of IOR). By manipulating the target response, Experiments 6 and 7 address the locus of the changes that occur within the information processing system when instructions to forget and remember are given. In this vein, in Experiment 6 we repeated the time-course methods of Experiment 4, except that a simple detection response was required for reporting the onset of the peripheral target. When IOR occurs for a simple detection response, it cannot be due to effects on response selection or to effects of explicitly mapping a spatial response to a visual onset (since there is only one response). It can, however, be due to early-stage effects that influence the speed of perceiving/attending to the peripheral onset or to late-stage effects in the speed of executing a response or in the setting of a single response criterion (see Chica, Taylor, Lupiáñez, \& Klein, 2009). If modulation of IOR by forget and remember instructions reflects changes in the information processing system at stages that are tapped by a detection task, this modulation should continue to be revealed in Experiment 6 .

\section{Method}

\section{Participants}

Data were initially collected from 60 undergraduate students who participated in exchange for course credit. Of these students, 3 were replaced with new participants: 2 because of computer problems that corrupted the data files, and 1 because the mean error rate to the target was more than two standard deviations higher than those of the remaining participants.

\section{Stimuli and apparatus}

The stimuli and apparatus were identical to those of Experiment 4, except that an online list generator (www. psy.uwa.edu.au/MRCDataBase/uwa_mrc.htm) was used to create two lists of 180 words each. The two lists were matched on Kučera-Francis word frequencies (cf. Kučera $\&$ Francis, $1967 ; M=103$ vs. $108, p>.70$ ), average number of letters $(R=4-5$, both $M \mathrm{~s}=5 ; t<1)$, concreteness $(M=484$ vs. $487, p>.76)$, and number of syllables (both $M \mathrm{~s}=1, p>.79$ ). Presentation of these lists as study words or foils was counterbalanced across participants within each tone designation.

\section{Procedure}

The procedure was identical to that of Experiment 4, with the following exceptions. The target response was changed from a spatially compatible choice localization to a simple 
detection response. Participants reported the detection of the target in either peripheral location by depressing the space bar on the computer keyboard with both thumbs. On $30 \%$ of the trials (catch trials), no peripheral target was presented. The instruction-target SOA was varied in the same manner as described for Experiment 4, except that the number of instruction-target SOAs was reduced to three $(75,300$, and $1,200 \mathrm{~ms})$ to accommodate the need to include no-target catch trials.

There were a total of 180 study trials, conceived as five repetitions of the factorial combination of word location (left, right), memory instruction (remember, forget), instruction-target SOA $(75,300,1,200 \mathrm{~ms})$, and target location (left, right). For the purpose of the analysis, we collapsed over same word-target location and different word-target location. In addition, there were 15 repetitions of the factorial combination of cue location (left, right) and memory instruction (remember, forget) that occurred without a subsequent target. Because cue location has no bearing on a catch trial (i.e., because there is no subsequent target to affect), left and right cue locations were collapsed in the analysis of catch trials.

\section{Results}

\section{Recognition}

During the recognition test, " $y$ " responses were made to $54 \%$ $(S E=2 \%)$ of remember words, $34 \%(S E=2 \%)$ of forget words, and $16 \%(S E=2 \%)$ of foil words. An analysis of these responses revealed a significant effect of word type, $F(2,118)=190.61, M S E=114.71, p<.01$. Planned comparisons confirmed an overall directed forgetting effect, with significantly more hits to remember than to forget words, $F(1,118)=103.82, p<.01$. As well, relative to unstudied foil items, participants responded " $\mathrm{y}$ " significantly more often to both remember, $F(1,118)=380.95, p<.01$, and forget, $F(1,118)=87.04, p<.01$, items.

\section{Target reaction times}

Target-present trials were considered correct if participants pressed the space bar once within $80-1,000 \mathrm{~ms}$ of target onset. RTs for correct trials and associated accuracies are shown in Fig. 5c.

The RTs for correct target detections were analyzed as a function of memory instruction (remember, forget), instruction-target SOA $(75,300,1,200 \mathrm{~ms})$, and word-target location (same, different). This analysis revealed a significant main effect of memory instruction, $F(1,59)=63.33$, $M S E=3,665.73, p<.01$, with overall slower RTs following forget, $M=510 \mathrm{~ms}(S E=5 \mathrm{~ms}$ ), than following remember, $M=474 \mathrm{~ms}(S E=4 \mathrm{~ms})$, instructions. There was a main effect of instruction-target SOA, reflecting overall faster RTs as a function of increasing SOA, $F(2,118)=36.16$, $M S E=6,713.48, p<.01$. There was also an overall IOR effect, confirmed by a significant main effect of wordtarget location, $F(1,59)=50.51, M S E=2,388.36, p<.01$; RTs were slower to targets that appeared in the same, $M=$ $505 \mathrm{~ms}(S E=5 \mathrm{~ms})$, rather than in a different, $M=479 \mathrm{~ms}$ $(S E=5 \mathrm{~ms})$, location relative to the word.

The only interaction that was significant was the two-way interaction of memory instruction and instruction-target SOA, $F(2,118)=22.25, M S E=1,976.05, p<.01$. This interaction reflects the finding that RTs were slower following forget than following remember instructions at the two shortest SOAs, but not at the longest SOA. There was no significant interaction of instruction-target SOA and word-target location, $F(2,118)=$ $1.78, M S E=1,874.03, p>.17$. There was also no significant interaction of memory instruction and word-target location, $F(1,59)=1.21, M S E=1,611.13, p>.27$. This indicates that the significant 23 -ms IOR effect on forget trials, $F(1,59)=$ $28.54, p<.01$, was not significantly different from the significant 29-ms IOR effect on remember trials, $F(1,59)=$ $47.54, p<.01$. The three-way interaction between memory instruction, instruction-target SOA, and word-target location did not even approach significance, $F<1$.

The percent accuracies on the target task were analyzed in an analogous ANOVA. This analysis revealed a significant main effect of instruction-target SOA, $F(2,118)=26.51$, $M S E=133.71, p<.01$, and an interaction of memory instruction and instruction-target SOA, $F(2,118)=24.47$, $M S E=90.25, p<.01$. The main effect and interaction both appeared to be driven by inexplicably low accuracy at the $1,200-\mathrm{ms}$ instruction-target interval in the remember condition, $M=81 \%(S E=1 \%)$, as compared to accuracies of $86 \%-93 \%$ across the remaining conditions. In any case, none of the other effects - including the critical three-way interaction of memory instruction, instruction-target SOA, and word-target location-were significant, all $p \mathrm{~s}>.14$.

\section{Catch trials}

The false alarms made on no-target catch trials were analyzed as a function of memory instruction (remember, forget). This analysis revealed a significant difference, $F(1,62)=34.19, M S E=23.28, p<.01$, with fewer false alarms following forget, $M=1 \%(S E=0.3 \%)$, than following remember, $M=6 \%(S E=0.8 \%)$, instructions.

\section{Discussion}

Experiment 6 again revealed a directed forgetting effect in recognition. There was also a significant overall IOR effect for the simple target detection task. This effect, however, was not significantly modulated by instructions to remem- 
ber or forget. When considered in light of the forget $>$ remember IOR difference that occurred for the localization response of Experiment 4, this suggests that the modulation of IOR by a memory instruction requires either a choice response in general or a choice response based on explicit target localization in particular. The forget $>$ remember IOR difference does not appear to be due to modulation of early perceptual/attentional processes; otherwise, IOR for a peripheral detection target would have been modulated in the same way by memory instructions as was IOR for a peripheral localization target.

Another interesting finding in Experiment 6 concerns the no-target catch trials. Consistent with findings reported by Fawcett and Taylor (2008; for further discussion, see Fawcett \& Taylor, 2010), fewer false alarms were made following forget than following remember instructions. Combined with an overall tendency for RTs to be slower following forget than following remember instructions, this suggests that memory instructions may involve a conservative criterion shift. The nature of such a shift will be considered more fully in the General Discussion.

\section{Experiment 7}

Experiment 7 required a choice response that reported the outcome of a perceptual discrimination. Thus, as in a localization task, participants needed to select between two response alternatives when responding to the target. Unlike in a localization task, however, the spatial location of the target was task irrelevant.

\section{Method}

\section{Participants}

Initially, 32 undergraduates volunteered in exchange for class credit. One of these participants was replaced due to reported confusion over the task requirements.

\section{Stimuli and apparatus}

The stimuli and apparatus were identical to those of Experiment 4, except for the target. The target was a black-filled equilateral triangle that was $2.5^{\circ}$ of visual angle on a side, presented in the center of a peripheral stimulus box, and oriented either with its apex at the top or the bottom of this box.

\section{Procedure}

The procedure was identical to that of Experiment 4, except for the target task. On a random half of the trials, the triangle target was presented in an upright orientation (apex at the top of the stimulus box), and on the other half of the trials it was presented in a downward orientation (apex at the bottom of the stimulus box). Participants were required to depress the "f" or " $\mathrm{j}$ " keys as quickly and accurately as possible to report the target orientation; the assignment of response keys to orientation was counterbalanced across participants within each of the counterbalanced levels of tone-memory instruction designation and word-foil list assignment. There were no catch trials.

There were a total of 160 study trials, conceptualized as two repetitions of the factorial combination of word location (left, right), memory instruction (remember, forget), instructiontarget SOA $(75,150,300,600,1,200 \mathrm{~ms})$, target orientation (upward, downward), and target location (left, right). For the analyses, word and target location were collapsed into same and different locations; the data were further collapsed over target orientations.

\section{Results}

Due to technical difficulties, data files obtained from 2 participants were incomplete and could not be used. The data from 2 other participants were eliminated due to target errors that exceeded two standard deviations of the overall mean. The data from the remaining 28 participants were analyzed.

\section{Recognition}

During the recognition test, " $y$ " responses were made to $61 \%$ $(S E=3 \%)$ of remember words, $31 \%(S E=3 \%)$ of forget words, and $11 \%(S E=2 \%)$ of foil words. An analysis of these responses revealed a significant effect of word type, $F(2,54)=181.10, M S E=100.63, p<.01$. Planned contrasts revealed a significant directed forgetting effect, with more hits to remember than to forget words, $F(1,54)=132.56, p<$ .01 . Relative to foil words, there were significantly more hits to both remember words, $F(1,54)=356.48, p<.01$, and forget words, $F(1,54)=54.27, p<.01$.

\section{Target reaction times}

RTs from trials on which a single correct discrimination response was made within $100-1,000 \mathrm{~ms}$ of target presentation were analyzed. These data are shown in Fig. 5d, along with associated percent accuracies.

The RT data were analyzed as a function of memory instruction (remember, forget), instruction-target SOA (75, $150,300,600,1,200 \mathrm{~ms}$ ), and word-target location (same, different). This analysis revealed a marginally significant effect of memory instruction, $F(1,27)=3.80, M S E=$ $3,020.60, p=.06$, with a trend for RTs to be longer 
following forget, $M=497 \mathrm{~ms}(S E=5 \mathrm{~ms})$, than following remember, $M=488 \mathrm{~ms}(S E=5 \mathrm{~ms})$, instructions. There was a significant main effect of instruction-target SOA, $F(4,108)=48.63, M S E=3,064.87, p<.01$, with RTs tending to decrease as a function of increasing SOA. An 8ms IOR effect was reflected in a marginally significant effect of word-target location, $F(1,27)=3.75, M S E=$ $2,053.72, p=.06$.

Neither the interaction of memory instruction and instruction-target $\operatorname{SOA}, F(4,108)=1.71, M S E=1,555.70, p>.15$, nor the interaction of instruction-target SOA and wordtarget location, $F<1$, was significant. Critically, the two-way interaction of memory instruction and word-target location was also not significant, $F(1,27)=1.33, M S E=904.67, p>$ .25. Nevertheless, planned comparisons were performed to determine the magnitude of any IOR effects obtained on remember and forget trials. These comparisons revealed a pattern opposite that of the previous experiments: There was a significant 11-ms IOR effect on remember trials, $F(1,27)=$ $8.28, p<.01$, but a nonsignificant 5-ms IOR effect on forget trials, $F(1,27)=1.55, p>.22$. The three-way interaction of memory instruction, instruction-target SOA, and wordtarget location did not even approach significance, $F<1$.

An analogous ANOVA was performed on the percent accuracies for the target task. None of the effects were significant, all $p \mathrm{~s}>.12$.

\section{Discussion}

In Experiment 7, participants made a choice buttonpress to report the outcome of a perceptual discrimination. Although there was a marginally significant overall IOR effect, there was no evidence for a forget $>$ remember difference in IOR magnitude. Indeed, to the contrary, planned comparisons revealed that there was a significant IOR effect on remember trials but not on forget trials. This is in stark contrast to a robust forget $>$ remember IOR difference for target localization.

A forget $>$ remember IOR difference that is specific to target localization could arise from the need to execute a response on the cued side of space per se, or from the need to execute a spatially compatible response toward the cued location. The former captures the idea that the intervening memory instruction will modulate any response in the cued direction; the latter captures the idea that it will modulate only responses that are made toward information that is presented in the cued location. To distinguish between these possibilities, we examined only those discrimination trials on which the required response happened to be spatially compatible with the cue (e.g., cue left-response "left"); due to the counterbalancing of target identity and response key, this occurred on half of all trials. The factorial ANOVA described in the results section (see above) was repeated using only those trials on which there was cue-response compatibility. This analysis revealed a significant main effect of instruction-target SOA, $F(4,108)=30.54, M S E=$ $5,532.91, p<.01$, with overall decreasing RTs with increasing SOA. There was also a marginally significant main effect of memory instruction, $F(1,27)=3.64, M S E=$ $6,572.02, p=.07$, with a tendency for RTs to be slower following forget, $M=501 \mathrm{~ms}(S E=5 \mathrm{~ms})$, than following remember, $M=487 \mathrm{~ms}(S E=5 \mathrm{~ms})$, instructions. No other effects were significant in the analyses of either RTs, all $p \mathrm{~s}>$ .33 , or accuracies, all $p \mathrm{~s}>.39$. The failure to find a forget $>$ remember IOR difference in the spatially compatible RTs argues against this difference arising from modulation of a generalized motor inhibition (see also Fawcett \& Taylor, 2010; Taylor \& Donnelly, 2002, Exp. 4). Instead, it appears to reflect modulation of a response made explicitly toward information in the peripheral word location. To the extent that the forget $>$ remember IOR difference is driven - in whole or in part-by magnification of IOR by the forget instruction, it may reflect an increased tendency to refrain from responding toward a location that had recently contained information that was deemed to be irrelevant. In this way, the forget $>$ remember IOR difference may reflect an adaptive measure that biases responses away from dubious sources of information and/or toward reliable sources.

\section{General discussion}

When an onset at center was used to pull exogenous attention away from the periphery, the forget $>$ remember IOR difference for target localization was not apparent; this was true whether the onset served as the memory instruction (Exp. 1) or was task irrelevant (Exp. 5). When the onset served as a memory instruction, it failed to produce a forget $>$ remember IOR difference, despite the fact that otherwise identical methods using a nonorienting auditory memory instruction (instead of a central visual onset) produced a robust difference with half as many participants (i.e., $n=16$ in Taylor, 2005, Exp. $1 ; n=32$ in the present Exp. 1). When the onset served as a task-irrelevant event interposed between an auditory memory instruction and target, it eliminated the robust forget $>$ remember IOR difference that would otherwise occur at the same word-instruction-target intervals (cf. Exp. 5 and Exp. 4). Importantly, the forget $>$ remember IOR difference was not similarly affected by the explicit manipulation of endogenous withdrawal. When target probabilities were manipulated to encourage the allocation of endogenous attention to center (Exp. 2), the forget $>$ remember IOR difference was again obtained for a localization response. Together, these data suggest that the modulation of IOR by a memory instruction depends on differential 
withdrawal of exogenous attention and not on instruction modality or the allocation of endogenous attention. When conditions enable differential withdrawal of exogenous attention, modulation of IOR by a memory instruction occurs across a wide range of instruction-target SOAs. This is true whether the instruction-target SOA covaries with wordinstruction SOA (Exp. 3) or with word-target SOA (Exp. 4).

The robust forget $>$ remember IOR difference that was obtained for target localization across a range of instruction-target SOAs was not readily observed for detection (Exp. 6) or perceptual discrimination (Exp. 7) responses. It is unlikely that the lack of a forget $>$ remember IOR difference for these two responses was due to a lack of statistical power. In the detection task of Experiment 6, data were analyzed for 60 participants, more than twice the sample size that had produced a reliable forget $>$ remember IOR difference in Experiments 2-4 (range: 22-29). The sample size used in the discrimination task of Experiment 7 $(n=29)$ was comparable to that of Experiments 2-4 but produced a difference in the opposite direction (i.e., there was significant IOR in the remember but not in the forget condition).

Eye movements were not monitored in the present experiments. This was a motivated feature of the design that took into account the fact that the nature of IOR changes as a function of whether the eyes are restrained or allowed to move in a more naturalistic way (see Chica et al., 2009; Taylor \& Klein, 2000). This leaves open a mundane explanation that the forget $>$ remember IOR difference was due solely to a strategy of orienting the eyes away from the location of the forget word and/or toward the location of the remember word. This seems unlikely for a number of reasons:

1. The study words had disappeared simultaneously with or up to several hundred milliseconds before the onset of the memory instruction. Given the time required to initiate an eye movement, this means that orienting the eyes in accordance with the memory instruction would provide no advantage in terms of increasing (in the case of remember trials) or decreasing (in the case of forget trials) the time available for perceptual processing of those words.

2. The forget $>$ remember IOR difference for target localization occurred even when the onset of the target was variable. If participants adopted a strategy of looking to the opposite location following a forget instruction, one might imagine that the response to the target would not be conceptualized by the participant as target localization but, instead, as a decision about whether the target appeared at the newly fixated location or not. To the extent that RTs for negative responses would be differentially slowed on forget relative to remember trials, this would have the effect of producing a forget $>$ remember IOR difference. The problem, however, is that this strategy would be very difficult to implement when the trial structure limits the temporal predictability of target onset. Yet a forget $>$ remember IOR difference occurred even in Experiment 4 , where the target onset was variable.

3. The forget $>$ remember IOR difference occurred even when target probabilities were highest at the center location (Exp. 2). Responses were fastest and most accurate to targets presented at that center location. Moreover, they did not differ at the center location following forget and remember instructions. This result is not easily interpreted in terms of strategic overt orienting differences on forget and remember trials; nevertheless, a forget $>$ remember IOR difference still occurred.

4. If participants adopted a strategy of looking away from the location at which a forget word had been presented (and/or toward the location of a remember word), this strategy should have been unaffected by the target task: A forget $>$ remember IOR difference should have occurred for all target tasks-localization, detection, and discrimination-since RTs to all of these tasks would have been affected by differences in overt orienting on forget and remember trials. However, this did not occur. The forget $>$ remember IOR difference occurred only when target localization was required.

We are confident in the strength of these arguments. Our data are inconsistent on all counts with the hypothesis that overt orienting differed on forget and remember trials. Although eye monitoring is the only sure way to measure overt orienting, the fact that such monitoring changes looking behavior generally (Risko \& Kingstone, 2011) and the manifestation of IOR specifically (Taylor \& Klein, 2000; see also Hunt \& Kingstone, 2003), it is not obvious that eye movement monitoring would clarify our interpretation. This is especially true given that the effect of repeating a target in the same location as a forget word seems to be a magnification of a response bias (see below); this effect is not detectable in behavior when the eyes are monitored (see Taylor \& Klein, 2000).

Accepting that the forget $>$ remember IOR difference is specific to target localization and cannot easily be explained by differences in overt orienting, we can address the questions our article set out to answer.

Why is IOR larger following forget than following remember instructions?

There are different views regarding the potential causes of IOR. It could be caused by covert (e.g., Posner, Rafal, 
Choate, \& Vaughan, 1985) and/or overt (e.g., Rafal, Calabresi, Brennan, \& Sciolto, 1989) attentional capture and withdrawal. Or it could arise as a result of the onset per se and exist at the same time as initial attentional facilitation (e.g., Dorris, Klein, Everling, \& Munoz, 2002; Ro \& Rafal, 1999; Tipper et al., 1997; see Klein, 2000, for a review). If IOR does arise at the same time as attentional facilitation, the effect would be obscured in behavior until that facilitation dissipates (cf. Müller \& Rabbitt, 1989) or is removed (cf. Danziger \& Kingstone, 1999). In any case, the bottom line is that IOR following a nonpredictive cue is usually revealed following the withdrawal of attentional resources (even though it may co-occur with endogenous dwell; see Berlucchi et al., 2000; Chica, 2008; Chica et al., 2006; Lupiáñez et al., 2004). As compared to no-memory control conditions, when a forget $>$ remember IOR difference occurs in the context of a memory task, it is due to a reliable magnification of IOR in the forget condition; this magnification of IOR following a forget instruction may or may not be accompanied by a reduction of IOR in the remember condition. Although it is unclear why the effect of a remember instruction on IOR is less reliable than that of a forget instruction, it may be related to the strategies employed by participants to elaborately rehearse the remember items. In any case, our results demonstrate that when a forget $>$ remember IOR difference occurs, it is most likely related to the differential withdrawal of exogenous, rather than endogenous, attention from the spatial representation of forget and remember words.

Interestingly, the forget $>$ remember IOR difference appears to be a consequence of the memory instruction per se and not a means by which that instruction is instantiated. If differential attentional withdrawal were the means by which the memory instruction was instantiated, the magnitude of the directed forgetting effect would be related to the magnitude of the forget $>$ remember IOR difference. Table 1 reveals obvious dissociations wherein a significant directed forgetting effect is obtained in all experiments, whereas a significant forget $>$ remember IOR difference is obtained in only a subset of experiments. Nevertheless, using the data from all seven experiments, we performed a simple regression that examined the directed forgetting effect (recognition: remember - forget) as a function of the IOR difference between forget and remember trials (collapsed across SOAs, where applicable). There was no significant relationship, $r=.08, t(226)=1.27, p>.20$. There was also no significant relationship when we limited our analysis to only those experiments that found an overall forget $>$ remember IOR difference with localization (Exps. 2, 3, and 4), $r=.08, t(72)<1$. In other words, neither analysis showed a significant relationship between the magnitude of the forget $>$ remember IOR difference and the magnitude of the directed forgetting effect.
We further analyzed the IOR data as a function of both the memory instruction (remember, forget) and the memory outcome on the subsequent recognition test (remembered, forgotten). If the magnitude of the IOR effect were related to the success of instantiating a forget memory instruction, we would expect a larger magnitude on forget trials for which the word was successfully forgotten versus remembered. However, recognition outcome failed to reach significance or interact with any of the other study variables when the IOR effects were analyzed across all seven experiments, all $p \mathrm{~s}>.10$, or when the analysis was limited to only those experiments that found a forget $>$ remember IOR difference (Exps. 2, 3, and 4), all $p \mathrm{~s}>.12$. These findings are puzzling, because in a previous experiment, Fawcett and Taylor (2010, Exp. 2) observed largermagnitude IOR following forget words that were later forgotten versus remembered (with no difference for remember trials), suggesting a link between the success of intentional forgetting and the magnitude of IOR. The source of the discrepancy between our previous single experiment and the present multiexperiment corpus is not clear. If the present data are to be believed, they suggest that rather than a causal relationship between attentional withdrawal and directed forgetting, any relationship is coincidental-at least where spatial representations of the learning episode are concerned.

In the context of this discussion, it is also pertinent to address the magnitude of the directed forgetting effects that were obtained in recognition across our experiments. As can be seen in Table 1, the magnitude of the directed forgetting effect varied from a low of $12 \%$ in Experiment 2 to a high of $35 \%$ in Experiment 1. The results from Experiment 1 can be discounted in light of the fact that this experiment provided intermittent recall trials in which participants were instructed to retrieve remember items only; this would likely have increased subsequent recognition of these items, and thus magnified the directed forgetting effect. Excluding Experiment 1, our range of directed forgetting effects was $12 \%-30 \%$ across the remaining experiments, with a mean of $21 \%$. Although this is a relatively large mean effect, it is unlikely to have been related to the dual-task requirements imposed by embedding the target task in the study trials of the item-method paradigm. Our other published work has produced similarsized item-method directed forgetting effects for recognition when no dual-task requirement was imposed. For example, Quinlan, Taylor, and Fawcett (2010) reported a directed forgetting effect of $20 \%$ when words were presented at study and test in an item-method directed forgetting task that did not impose any dual-task requirements; a similar, $18 \%$ effect was reported by Wylie, Foxe, and Taylor (2008), and a 17\% effect was reported by Hourihan et al. (2007). 
What are the implications of larger IOR following forget than following remember instructions?

To determine the implications of a forget $>$ remember IOR difference for information processing, it is necessary to consider the nature of the IOR effect and what this magnitude difference might reflect. In a paradigm that had no memory component, Taylor and Ivanoff (2003) measured the magnitude of the IOR effect following an instruction to stop a prepotent motor response. Relative to when the response was correctly executed on a go trial, receipt of a countermanding instruction increased the magnitude of the IOR effect. This was true whether the initial countermanded response was successfully canceled or not, but it did depend on the same effectors being used for both the countermanded and target responses. On the basis of these findings, Taylor and Ivanoff argued that the mechanism underlying the IOR effect shares late-stage processing with motor inhibition (see also Ivanoff \& Taylor, 2006).

The interaction of the IOR effect and motor inhibition in a stop signal paradigm has implications for understanding the present findings, because intentional forgetting may involve similar (e.g., Hourihan \& Taylor, 2006), even if not identical (see Fawcett \& Taylor, 2010), control mechanisms to the ones engaged in the inhibition of a prepotent overt response (see Anderson, 2003). Conceptually and behaviorally, there are similarities between the cessation of covert rehearsal and the prevention of an unwanted overt response (e.g., cf. Hourihan \& Taylor, 2006, with Logan, 1983, 1985; Logan \& Barber, 1985; Zbrodoff \& Logan, 1986). Neural parallels were identified by functional magnetic resonance imaging during the study phase of an itemmethod directed forgetting task (Wylie et al., 2008). On forget trials, Wylie et al. observed greater activity in inferior frontal gyrus when to-be-forgotten words were later successfully forgotten than when they were recognized. Importantly, regions of the inferior frontal gyrus are also active during the successful stopping of unwanted overt responses (e.g., Aron, Fletcher, Bullmore, Sahakian, \& Robbins, 2003; Rieger, Gauggel, \& Burmeister, 2003) and have been implicated in the ventral attentional system that is associated with exogenous attention (see Corbetta \& Shulman, 2002). If item-method directed forgetting thereby operates in a way that is analogous to motor response inhibition (cf. Hourihan \& Taylor, 2006; Wylie et al., 2008), motor response inhibition interacts with the IOR effect (cf. Ivanoff \& Taylor, 2006; Taylor \& Ivanoff, 2003), and all three share neural circuitry (cf. Aron et al., 2003; Corbetta \& Shulman, 2002; Wylie et al., 2008), then it is not surprising that instructions to remember and forget also interact with the IOR effect. The fact that they do is consistent with the interaction being a late-stage effect.
Despite the poor choice of nomenclature (Berlucchi, 2006), "inhibition of return" does not necessarily represent the inhibited return of attention to a previously attended location (Abrams \& Dobkin, 1994; Hunt \& Kingstone, 2003; Kingstone \& Pratt, 1999; Taylor \& Klein, 2000). There are certainly times when this seems to be the case (e.g., Handy, Jha, \& Mangun, 1999; Prime \& Ward, 2004; Reuter-Lorenz, Jha, \& Rosenquist, 1996). However, when the eyes are not actively prevented from moving (cf. Taylor \& Klein, 2000) - as in the present study - the IOR effect appears to reflect the operation of a criterion-shift that slows the execution of responses to targets that appear at the affected location (cf. Klein \& Taylor, 1994; see Taylor $\&$ Klein, 1998, for a review). Thus, regardless of the cause (s) of this effect, once developed, it is expressed as a reluctance to respond to targets at the cued location (cf. Klein \& Taylor, 1994; e.g., Ivanoff, 2004; Ivanoff \& Klein, 2006; Ivanoff \& Taylor, 2006; Taylor \& Ivanoff, 2003) when the eyes are free to move (cf. Taylor \& Klein 2000; see also Hunt \& Kingstone, 2003). As a result, RTs are slowed to targets that appear in the same location as the initial onset, relative to targets that appear in a different location. As well, false alarms are less frequent when nontarget events occur in the same location as the initial onset rather than in a different location (Ivanoff \& Klein, 2001, 2004; Taylor \& Ivanoff, 2003). And, as observed by Ivanoff and Taylor (2006), countermanded responses are less likely to be executed erroneously when the target location is subject to IOR.

The fact that the forget $>$ remember IOR difference occurs for target localization and not for detection or discrimination in the present study suggests that modulation of IOR by a memory instruction does not occur at perceptual/attentional or response selection stages of information processing. It also does not occur at motor output stages (see the response compatibility analysis of the discrimination data in Exp. 6; see also Fawcett \& Taylor, 2010). Understanding this conclusion depends on a clear understanding of the distinction between the generation of IOR by a peripheral onset event (in this case, the word) and the measurement of the IOR effect by target RTs (see Taylor \& Klein, 1998, 2000). In our task, we are presuming that the onset of the peripheral word initiates IOR (see Dorris et al., 2002); it is the onset itself that generates IOR, and this IOR effect is independent of attention (e.g., Ro \& Rafal, 1999; Tipper et al., 1997)—even though the continued lingering of attention can mask the effects of IOR in behavior (see Posner \& Cohen, 1984). When the memory instruction is presented, there is a differential withdrawal of exogenous attention such that attention is withdrawn more readily following forget than following remember instructions. A withdrawal of attention "unmasks" the IOR effect that was laid down by the onset 
of the peripheral word (cf. Danziger \& Kingstone, 1999). There are no implications of this withdrawal for the subsequent reallocation of exogenous attention to the onset target. That is, attention may be attracted to the target as readily whether it appears in the cued or the uncued location, and perceptual processing of the target may thereby proceed unimpaired. Indeed, the latter must be true, because if there were impaired attentional/perceptual processing at the word location, the forget $>$ remember IOR difference would have been observed for all targets, regardless of their required response. Instead, it was observed only for target localization. This suggests that the magnification of the IOR effect on forget relative to remember trials is unrelated to attention or its effects on the speed (e.g., Carrasco \& McElree, 2001) and quality (cf. Posner, 1980; see, e.g., Carrasco, Penpeci-Talgar, \& Eckstein, 2000) of perceptual processing. Instead, if we can assume that the control processes engaged by forget and remember instructions are the same in localization, detection, and discrimination tasks, then a plausible interpretation for our pattern of data is that the modulation of IOR by memory instruction arises from a tendency to take into account the quality of a recent source of information. ${ }^{2}$ To the extent that the forget $>$ remember IOR difference owes its existence - in whole or in part - to magnification of IOR in the forget condition (i.e., with or without a concomitant decrease of IOR in the remember condition), this suggests a bias against making a response explicitly toward a location that was a recent source of irrelevant information.

Interestingly, the data from the present experiments suggest that differential attentional withdrawal is not causal in determining which memory traces will be strong enough to support recognition in the long term (although see Fawcett \& Taylor, 2010). If it were, we would have expected a reliable relationship between directed forgetting and the forget $>$ remember IOR difference that arises from the modulation of exogenous withdrawal. Even if this

\footnotetext{
${ }^{2}$ To assume otherwise would require that the target task establish an attentional control setting that influences the way in which the memory instruction interacts with attention. There is certainly evidence that attentional control settings can be established by the target task and can influence the time course of the IOR effects that are generated by a peripheral onset cue (e.g., Klein, 2000). However, the fact that we observe the forget $>$ remember IOR difference across a range of SOAs for localization but not for detection and discrimination makes us think that it is not simply an issue of the memory instruction interacting with the attentional control setting established by the target task. If it were, we would have expected the forget $>$ remember IOR difference to emerge at some point in our time-course analyses-even if earlier for detection and later for discrimination tasks, relative to localization. The fact that we did not observe a forget $>$ remember IOR difference across our time-course manipulations makes us believe that we are tapping into something other than an interaction of memory instruction and the task-based attentional/cognitive set.
}

conclusion is borne out, and attention proves not to be causal with respect to determining the fate of an item that has already entered working memory (i.e., a word that is subsequently "forget" instructed), it may still aid efficient information processing in the short term by biasing responses away from the source of irrelevant information.

This notion that source information forms part of the mental representation of forget and remember items is not implausible. Hourihan et al. (2007) showed that, even when task irrelevant, the location of peripherally presented words is automatically encoded at study. The results of the present study suggest that not only does source information become part of the episodic representation that is formed at study, but its reliability is also assessed and used to guide responses that follow soon thereafter. This kind of mechanism may not normally come to bear in a standard item-method directed forgetting task, for which all words are presented in a single location. But in the real world, information comes from numerous sources whose reliability may need to be assessed to ensure that limited-capacity resources are not consumed with directing responses based on outdated or irrelevant information.

\section{Conclusion}

To conclude, the present study suggests that exogenous attention is differentially withdrawn from the spatial representation of peripherally presented forget and remember words, but that this differential attentional withdrawal is an automatic consequence of an intention to remember or forget, and not the mechanism by which that intention is instantiated. Instead, the larger-magnitude IOR effect on forget trials than on remember trials that is revealed by the differential withdrawal of exogenous attention reflects a bias against making responses toward the source of irrelevant information. This bias operates in conjunction with the IOR effect initiated by peripheral word onset to magnify the effect on forget relative to remember trials. Although this bias does not appear to have long-term consequences for the recognition of forget and remember words, and therefore cannot be the mechanism that underlies directed forgetting, it likely does serve memory by limiting the ability of unreliable sources of information to govern responding. Although this has no long-term or direct effect on the word that was issued from the unreliable source, it does limit this source from continuing to engage limited-capacity resources in the short term. There does not appear to be a delay in perceptual processing. Instead, the short-term bias against responding toward an unreliable source likely allows continued accumulation of information from that source; this delay would provide an opportunity for the source to be reevaluated before committing resources to the information that it provides. 
Author Note We thank Alison Moss, Kate Thompson, Tom Howells, Chelsea Quinlan, and Emily Nichols for their help collecting and/or collapsing data; Carl Helmick for writing custom software to randomize word presentation and collapse data; and our undergraduate participants for volunteering to take part in this study. We also acknowledge the helpful feedback we received from Bruce Milliken, Colin MacLeod, and an anonymous reviewer. This research was supported by an NSERC Discovery Grant to T.L.T. and by an NSERC CGS doctoral scholarship and Killam scholarship to J.M.F.

\section{References}

Abrams, R. A., \& Dobkin, R. S. (1994). Inhibition of return: Effects of attentional cuing on eye movement latencies. Journal of Experimental Psychology: Human Perception and Performance, 20, 467-477.

Anderson, M. C. (2003). Rethinking interference theory: Executive control and the mechanisms of forgetting. Journal of Memory and Language, 49, 415-445.

Aron, A. R., Fletcher, P. C., Bullmore, E. T., Sahakian, B. J., \& Robbins, T. W. (2003). Stop-signal inhibition disrupted by damage to right inferior frontal gyrus in humans. Nature Neuroscience, 6, 115-116.

Bartolomeo, P., Decaix, C., \& Siéroff, E. (2007). The phenomenology of endogenous orienting. Consciousness and Cognition, 16, 144161. doi:10.1016/j.concog.2005.09.002

Basden, B. H., \& Basden, D. R. (1998). Directed forgetting: A contrast of methods and interpretations. In J. M. Golding \& C. M. MacLeod (Eds.), Intentional forgetting: Interdisciplinary approaches (pp. 139-172). Mahwah, NJ: Erlbaum.

Basden, B. H., Basden, D. R., \& Gargano, G. J. (1993). Directed forgetting in implicit and explicit memory tests: A comparison of methods. Journal of Experimental Psychology: Learning, Memory, and Cognition, 19, 603-616.

Berlucchi, G. (2006). Inhibition of return: A phenomenon in search of a mechanism and a better name. Cognitive Neuropsychology, 23, 1065-1074. doi:10.1080/02643290600588426

Berlucchi, G., Chelazzi, L., \& Tassinari, G. (2000). Volitional covert orienting to a peripheral cue does not suppress cue-induced inhibition of return. Journal of Cognitive Neuroscience, 12, 648663.

Bjork, R. A. (1970). Positive forgetting: The noninterference of items intentionally forgotten. Journal of Verbal Learning and Verbal Behavior, 9, 255-268.

Bjork, R. A. (1972). Theoretical implications of directed forgetting. In A. W. Melton \& E. Martin (Eds.), Coding processes in human memory (pp. 217-235). Washington, DC: Winston.

Bjork, R. A. (1989). Retrieval inhibition as an adaptive mechanism in human memory. In H. L. Roediger III \& F. I. M. Craik (Eds.), Varieties of memory and consciousness: Essays in honor of Endel Tulving (pp. 309-330). Hillsdale, NJ: Erlbaum.

Bjork, E. L., \& Bjork, R. A. (1996). Continuing influences of to-beforgotten information. Consciousness and Cognition, 5, 176-196.

Bjork, R. A., \& Woodward, A. E. (1973). Directed forgetting of individual words in free recall. Journal of Experimental Psychology, 99, 22-27.

Briand, K. A., \& Klein, R. M. (1987). Is Posner's "beam" the same as Treisman's "glue"? On the relation between visual orienting and feature integration theory. Journal of Experimental Psychology: Human Perception and Performance, 13, 228-241. doi:10.1037/ 0096-1523.13.2.228

Carrasco, M., \& McElree, B. (2001). Covert attention accelerates the rate of visual information processing. Proceedings of the National Academy of Sciences, 98, 5363-5367.
Carrasco, M., Penpeci-Talgar, C., \& Eckstein, M. (2000). Spatial covert attention increases contrast sensitivity across the CSF: Support for signal enhancement. Vision Research, 40, 1203 1215. doi:10.1016/S0042-6989(00)00024-9

Chica, A. B. (2008). Differential effects of endogenous and exogenous attention on information processing (Unpublished doctoral dissertation). Granada, Spain: University of Granada.

Chica, A. B., Lupiáñez, J., \& Bartolomeo, P. (2006). Dissociating inhibition of return from endogenous orienting of spatial attention: Evidence from detection and discrimination tasks. Cognitive Neuropsychology, 23, 1015-1034.

Chica, A. B., Taylor, T. L., Lupiáñez, J., \& Klein, R. M. (2009). Two mechanisms underlying inhibition of return. Experimental Brain Research, 201, 25-35. doi:10.1007/s00221-009-2004-1

Cohen, J. D., MacWhinney, B., Flatt, M., \& Provost, J. (1993). PsyScope: An interactive graphic system for designing and controlling experiments in the psychology laboratory using Macintosh computers. Behavior Research Methods, Instruments, \& Computers, 25, 257-271.

Corbetta, M., \& Shulman, G. L. (2002). Control of goal-directed and stimulus driven attention in the brain. Nature Reviews Neuroscience, 3, 201-215.

Craik, F. I. M., \& Lockhart, R. S. (1972). Levels of processing: A framework for memory research. Journal of Verbal Learning and Verbal Behavior, 11, 671-684.

Craik, F. I. M., \& Watkins, M. J. (1973). The role of rehearsal in shortterm memory. Journal of Verbal Learning and Verbal Behavior, 12, 599-607.

Danziger, S., \& Kingstone, A. (1999). Unmasking the inhibition of return phenomenon. Perception \& Psychophysics, 61, 1024 1037.

Dorris, M. C., Klein, R. M., Everling, S., \& Munoz, D. P. (2002). Contribution of the primate superior colliculus to inhibition of return. Journal of Cognitive Neuroscience, 14, 1256-1263.

Fawcett, J. M., \& Taylor, T. L. (2008). Forgetting is effortful: Evidence from reaction time probes in an item-method directed forgetting task. Memory \& Cognition, 36, 1168-1181.

Fawcett, J. M., \& Taylor, T. L. (2010). Directed forgetting shares mechanisms with attentional withdrawal but not stop-signal inhibition. Memory \& Cognition, 38, 797-808.

Gardiner, J. M., Gawlick, B., \& Richardson-Klavehn, A. (1994). Maintenance rehearsal affects knowing, not remembering: Elaborative rehearsal affects remembering, not knowing. Psychonomic Bulletin \& Review, 1, 107-110.

Gottlob, L. R., Golding, J. M., \& Hauselt, W. J. (2006). Directed forgetting of a single item. The Journal of General Psychology, $133,67-80$.

Handy, T. C., Jha, A. P., \& Mangun, G. R. (1999). Evidence for an attention component in inhibition of return. Psychological Science, 10, 157-161.

Hourihan, K. L., Goldberg, S., \& Taylor, T. L. (2007). The role of spatial location in remembering and forgetting peripheral words. Canadian Journal of Experimental Psychology, 61, 91-101.

Hourihan, K. L., \& Taylor, T. L. (2006). Cease remembering: Control processes in directed forgetting. Journal of Experimental Psychology: Human Perception and Performance, 32, 1354-1365.

Hunt, A. R., \& Kingstone, A. (2003). Inhibition of return: dissociating attentional and oculomotor components. Journal of Experimental Psychology: Human Perception and Performance, 29, 10681074.

Ivanoff, J. G. S. (2004). On the information processing dynamics of inhibition of return. Dissertation Abstracts International: Section B. Sciences and Engineering, 64(9B), 464.

Ivanoff, J., \& Klein, R. M. (2001). The presence of a nonresponding effector increases inhibition of return. Psychonomic Bulletin \& Review, 8, 307-314. 
Ivanoff, J., \& Klein, R. M. (2004). Stimulus-response expectancies and inhibition of return. Psychonomic Bulletin \& Review, 11, $542-550$.

Ivanoff, J., \& Klein, R. M. (2006). Inhibition of return: Sensitivity and criterion as a function of response time. Journal of Experimental Psychology: Human Perception and Performance, 32, 908-919.

Ivanoff, J., \& Taylor, T. L. (2006). Inhibition of return promotes stopsignal inhibition by delaying responses. Visual Cognition, 13, 503-512.

Kingstone, A., \& Pratt, J. (1999). Inhibition of return is composed of attentional and oculomotor processes. Perception \& Psychophysics, 61, 1046-1054.

Klein, R. M. (2000). Inhibition of return. Trends in Cognitive Sciences, 4, 138-147.

Klein, R. M., \& Taylor, T. L. (1994). Categories of cognitive inhibition, with reference to attention. In D. Dagenbach \& T. H. Carr (Eds.), Inhibitory processes in attention, memory, and language (pp. 113-150). San Diego, CA: Academic Press.

Kučera, H., \& Francis, W. N. (1967). Computational analysis of presentday American English. Providence, RI: Brown University Press.

Logan, G. D. (1983). On the ability to inhibit simple thoughts and actions: I. Stop-signal studies of decision and memory. Journal of Experimental Psychology: Learning, Memory, and Cognition, 9, 585-606.

Logan, G. D. (1985). On the ability to inhibit simple thoughts and actions: II. Stop-signal studies of repetition priming. Journal of Experimental Psychology: Learning, Memory, and Cognition, 11, 675-691.

Logan, G. D., \& Barber, C. Y. (1985). On the ability to inhibit complex thoughts: A stop-signal study of arithmetic. Bulletin of the Psychonomic Society, 23, 371-373.

Lupiáñez, J., Decaix, C., Siéroff, E., Chokron, S., Milliken, B., \& Bartolomeo, P. (2004). Independent effects of endogenous and exogenous spatial cueing: Inhibition of return at endogenously attended target locations. Experimental Brain Research, 159, $447-457$.

MacLeod, C. M. (1989). Directed forgetting affects both direct and indirect tests of memory. Journal of Experimental Psychology: Learning, Memory, and Cognition, 15, 13-21.

MacLeod, C. M. (1998). Directed forgetting. In J. M. Golding \& C. M. MacLeod (Eds.), Intentional forgetting: Interdisciplinary approaches (pp. 1-57). Mahwah, NJ: Erlbaum.

MacLeod, C. M. (1999). The item and list methods of directed forgetting: Test differences and the role of demand characteristics. Psychonomic Bulletin \& Review, 6, 123-129.

Müller, H. J., \& Rabbitt, P. M. A. (1989). Reflexive and voluntary orienting of visual attention: Time course of activation and resistance to interruption. Journal of Experimental Psychology: Human Perception and Performance, 15, 315-330.

Posner, M. I. (1980). Orienting of attention. The Quarterly Journal of Experimental Psychology, 32, 3-25.

Posner, M. I. (1992). Attention as a cognitive and neural system. Current Directions in Psychological Science, 1, 11-14.

Posner, M. I., \& Cohen, Y. (1984). Components of visual orienting. In H. Bouma \& D. Bouwhuis (Eds.), Attention and performance $X$ (pp. 531-556). Hillsdale, NJ: Erlbaum.

Posner, M. I., Rafal, R. D., Choate, L. S., \& Vaughan, J. (1985). Inhibition of return: Neural basis and function. Cognitive Neuropsychology, 2, 211-228.

Prime, D. J., \& Ward, L. M. (2004). Inhibition of return from stimulus to response. Psychological Science, 15, 272-276.

Quinlan, C. K., Taylor, T. L., \& Fawcett, J. M. (2010). Directed forgetting: Comparing pictures and words. Canadian Journal of Experimental Psychology, 64, 41-46.

Rafal, R. D., Calabresi, P. A., Brennan, C. W., \& Sciolto, T. K. (1989). Saccade preparation inhibits reorienting to recently attended locations. Journal of Experimental Psychology: Human Perception and Performance, 15, 673-685.

Reuter-Lorenz, P. A., Jha, A. P., \& Rosenquist, J. N. (1996). What is inhibited in inhibition of return? Journal of Experimental Psychology: Human Perception and Performance, 22, 367-378.

Rieger, M., Gauggel, S., \& Burmeister, K. (2003). Inhibition of ongoing responses following frontal, nonfrontal, and basal ganglia lesions. Neuropsychology, 17, 272-282. doi:10.1037/ 0894-4105.17.2.272

Risko, E. F., \& Kingstone, A. (2011). Eyes wide shut: implied social presence, eye tracking and attention. Attention, Perception, \& Psychophysics, 73, 291-296.

Risko, E. F., \& Stoltz, J. A. (2010). The proportion valid effect in covert orienting: Strategic control or implicit learning? Consciousness and Cognition, 19, 432-442.

Ro, T., \& Rafal, R. D. (1999). Components of reflexive visual orienting to moving objects. Perception \& Psychophysics, 61, 826-836.

Roediger, H. L., \& Crowder, R. G. (1972). Instructed forgetting: Rehearsal control or retrieval inhibition (repression)? Cognitive Psychology, 3, 244-254. doi:10.1016/0010-0285(72)90006-0

Samuel, A. G., \& Kat, D. (2003). Inhibition of return: A graphical metaanalysis of its time course and an empirical test of its temporal and spatial properties. Psychonomic Bulletin \& Review, 10, 897-906.

Stone, J. V., Hunkin, N. M., Porrill, J., Wood, R., Keeler, V., Beanland, M., et al. (2001). When is now? Perception of simultaneity. Proceedings of the Royal Society B, 268, 31-38. doi:10.1098/rspb.2000.1326

Taylor, T. L. (2005). Inhibition of return following instructions to remember and forget. The Quarterly Journal of Experimental Psychology, 58A, 613-629 (Erratum in 58A, 1343).

Taylor, T. L., \& Donnelly, M. P. W. (2002). Inhibition of return for target discriminations: The effect of repeating discriminated and irrelevant stimulus dimensions. Perception \& Psychophysics, 64, 292-317.

Taylor, T. L., \& Ivanoff, J. (2003). The interplay of stop signal inhibition and inhibition of return. The Quarterly Journal of Experimental Psychology, 56A, 1349-1371.

Taylor, T. L., \& Klein, R. M. (1998). On the causes and effects of inhibition of return. Psychonomic Bulletin \& Review, 5, 625-643.

Taylor, T. L., \& Klein, R. M. (2000). Visual and motor effects in IOR. Journal of Experimental Psychology: Human Perception and Performance, 26, 1639-1656.

Taylor, T. L., \& Therrien, M. E. (2005). Inhibition of return for faces. Perception \& Psychophysics, 67, 1414-1422.

Tekcan, A. I., \& Aktürk, M. (2001). Are you sure you forgot? Feeling of knowing in directed forgetting. Journal of Experimental Psychology: Learning, Memory, and Cognition, 27, 1487-1490.

Tipper, S. P., Rafal, R., Reuter-Lorenz, P. A., Starrveldt, Y., Ro, T., Egly, R., et al. (1997). Object-based facilitation and inhibition from visual orienting in the human split-brain. Journal of Experimental Psychology: Human Perception and Performance, 23, 1522-1532.

Wetzel, C. D., \& Hunt, R. E. (1977). Cue delay and the role of rehearsal in directed forgetting. Journal of Experimental Psychology: Human Learning and Memory, 3, 233-245.

Woodward, A. E., Bjork, R. A., \& Jongeward, R. H. (1973). Recall and recognition as a function of primary rehearsal. Journal of Verbal Learning and Verbal Behavior, 12, 608-617.

Wylie, G. R., Foxe, J. J., \& Taylor, T. L. (2008). Forgetting as an active process: An fMRI investigation of item-method directed forgetting. Cerebral Cortex, 18, 670-682.

Zacks, R. T., Radvansky, G., \& Hasher, L. (1996). Studies of directed forgetting in older adults. Journal of Experimental Psychology: Learning, Memory, and Cognition, 22, 143-156.

Zbrodoff, N. J., \& Logan, G. D. (1986). On the autonomy of mental processes: A case study of arithmetic. Journal of Experimental Psychology: General, 115, 118-130. 